\title{
The voices of Samoan parents and their children: home reading practices and home-school connections
}

\author{
Sarah Valentine
}

\begin{abstract}
A thesis
submitted to the Victoria University of Wellington

in fulfilment of the requirements for the degree of

Master of Education
\end{abstract}

Victoria University of Wellington

2014 


\begin{abstract}
This thesis investigates Samoan parents and their primary school aged children's experiences and perceptions of learning to read and the role this plays in home reading practices. A key purpose was to investigate what can be learnt from Samoan born parents regarding their cultural values and understandings around learning to read. Gaining understandings of the influences and experiences these parents have had when learning to read in Samoa would provide insights into the home reading practices being used with their own children. By examining the parents' cultural values and practices, possible connections or disconnections between home and school reading practices can be drawn.
\end{abstract}

While home and school partnerships are deemed to be important in New Zealand primary schools and by the Ministry of Education there needs to be improved understandings of the cultural values and practices that are taking place within many Samoan households regarding reading instruction. The valuing of these practices also needs to be considered with the understanding that there are diverse forms of literacy across cultural communities. The focus has been on how school reading practices can be implemented into the home environment rather than what can be learnt from home practices. This thesis has aimed to amend this by acknowledging and giving voice to Samoan born parents through discussing their own reading practices and experiences, and the influence this has had on the strategies they use when reading with their children.

Pasifika students' learning and achievement within New Zealand schools has been identified as a key priority for the Ministry of Education. The recent Pasifika Education Plan 2013-2017 (Ministry of Education, 2013) has outlined specific goals and targets aimed at improving Pasifika educational achievement that include establishing stronger connections between home and school for Pasifika learners. If connections are to be made the influence of social and cultural factors on students' learning and achievement needs to be identified and valued.

The methodology used was qualitative in design. A case study approach that integrated a socio-cultural perspective and the practices of Pasifika research 
methodology were used to allow for literacy to be seen as social practice where peoples' views, values and experiences are used to enhance understandings of the role social and cultural factors play within education.

Data collection was through Talanoa ${ }^{1}$ individual interview sessions with five Samoan born parent participants individually. Two Talanoa sessions were held with each parent. The parent participants' eldest children were then interviewed in pairs. The voices of the participants were used to gain insights into cultural perceptions of reading practices within school and home contexts. The parent participants' knowledge of school reading practices was also sought. The research data was analysed by using Rogoff's three planes of analysis (1995). Rogoff's framework was used to interpret the key themes as they relate to the connections and/or disconnections between home and school reading practices.

The research findings indicate that strong cultural reading values and practices are in place for these Samoan parent participants. The practices being employed have been formed from their own experiences and memories of learning to read as children, in Samoa. These reading practices are based on the cultural values and actions that have been previously identified in literature on Samoan literacy (McNaughton, AmitanaiToloa \& Wolfgramm-Foliaki, 2009; Duranti \& Ochs, 1993; Duranti, Ochs \& Ta'ase 2004; Tagoilelagi, 1995; Tuafuti, 2000). As parents, these participants have continued to use these reading strategies and practices with their own children in New Zealand. Another key finding was that the parent participants' knowledge of school reading practices in New Zealand was found to be limited. This finding in combination with the cultural home reading practices being employed has strong implications for home and school connections between Samoan communities and primary schools within New Zealand.

\footnotetext{
${ }^{1}$ Talanoa, a traditional Pasifika term known as a talking methodology
} 


\section{ACKNOWLEDGEMENTS}

Firstly to the parent participants involved in this research for agreeing to participate and give up their time to be interviewed. It was a privilege to be able to hear their openness and honest recounts of their experiences of learning to read in Samoa. The individual personal recounts they told have allowed me to gain a greater understanding of the cultural beliefs held regarding reading, which I will treasure as both an individual and educator. These parent participants also allowed me to interview their children, which I am grateful for, as it has given a richer picture to this research and greater voice to understanding their home reading practices.

A huge fa'afetai to them all.

I wish to thank the Principal of the selected school for allowing me to carry out my research within a familiar primary school environment to myself and the participants, in a trusting and supportive way with a belief that the voices of the school's Samoan parents should be heard and valued.

Finally I wish to acknowledge my supervisor Dr John Dickie for his on going guidance and support in completing my thesis and his belief that I had something worthwhile to say. His patience and thoughtful insights were much appreciated. I would also like to acknowledge the initial support received from Fuapepe Rimoni regarding Pasifika methodology. 


\section{CHAPTER ONE: INTRODUCTION}

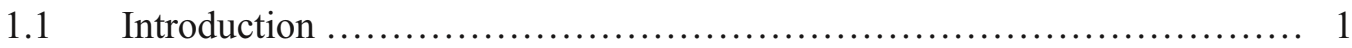

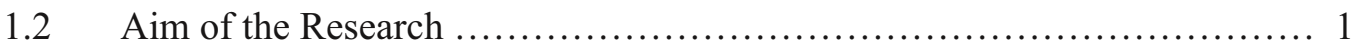

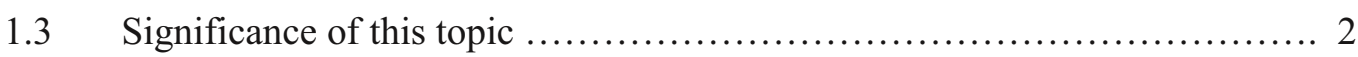

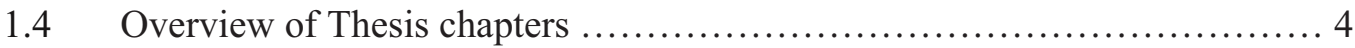

\section{CHAPTER TWO: ITERATURE REVIEW}

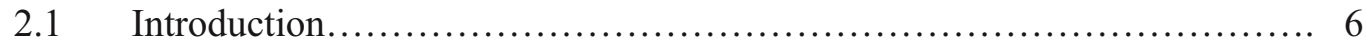

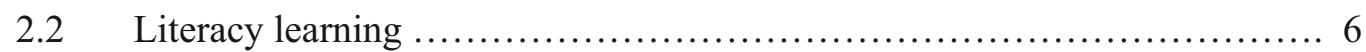

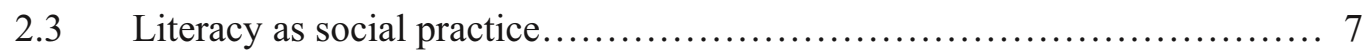

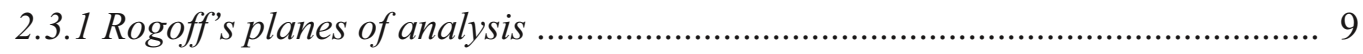

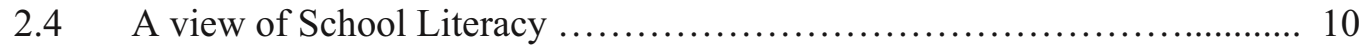

2.5 Reading practices in a New Zealand context f...................... 13

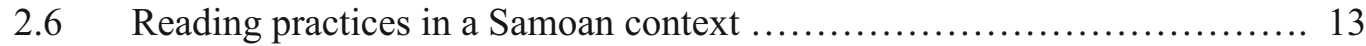

$2.7 \quad$ A view of Home Literacy .......................................... 16

2.8 Home/School Relationships ................................... 18

2.9 Looking at Pasifika/School Partnerships ........................... 20

2.10 Positioning this research thesis .................................... 23

\section{CHAPTER THREE: METHODOLOGY}

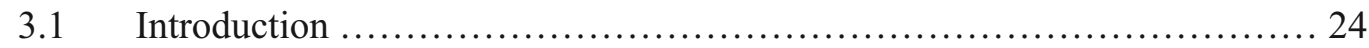

3.2 The Research Questions ........................................... 24

3.3 The Theoretical Framework...................................... 24

3.4 Pasifika Research Methodology ................................. 27

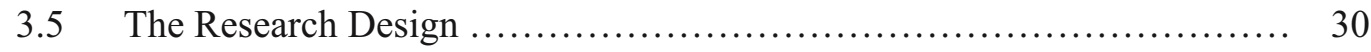


3.5.2 Participants.................................................... 30

3.6 Data Collection ...................................................... 31

3.6.1 Initial consultation meeting ........................................ 31

3.6.2 Parent Talanoa Interview One .................................... 33

3.6.3 Parent Talanoa Interview Two .................................... 34

3.6.4 Student Group ...................................................... 35

3.7 Data Analysis

3.7.1 Rogoff's three planes of analysis ........................................ 36

3.8 Ethical considerations ............................................... 37

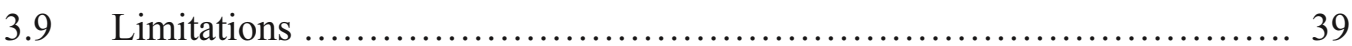

\section{CHAPTER FOUR; $\quad$ FINDINGS AND DISCUSSION:}

\section{A SAMOAN CONTEXT}

$4.1 \quad$ Introduction ...................................................... 41

4.2 Three literacy sites: Pastor's School, Primary School, Home ............ 43

4.3 Three reading themes: Oral language, Rote learning, Decoding .......... 44

4.3.1 Oral Language - listening, reciting and singing .................................... 46

4.3.2 Rote learning-memorization, repetition and practice ................. 51

4.3.3 Decoding - sounding out, correct pronunciation...................... 56

4.4 Access to Literacy resources...................................... 57

4.5 Final Thoughts ................................................... 59 


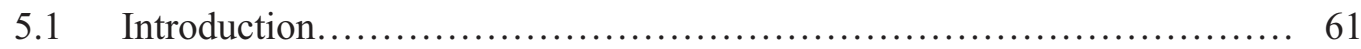

5.2 Section One: Parent reading practices with their children in New Zealand... 62

5.3 The Five Parent Participants' descriptions ............................ 62

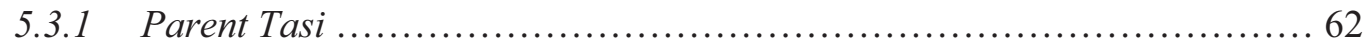

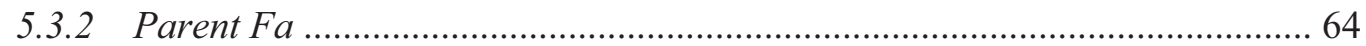

5.3 .3 Parent Tolu ...................................................... 68

5.3 .4 Parent Lua .................................................... 70

5.3 .5 Parent Lima ................................................. 73

5.3 .6 Some common threads ........................................... 75

5.4 Section Two: The children's responses to identify home reading practices

5.5 Section Three: Parent knowledge of school reading practices in New Zealand

5.6 Connections or Disconnections between home and school reading practices

\section{CHAPTER SIX: CONCLUSIONS AND RECOMMENDATIONS}

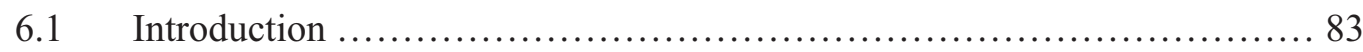

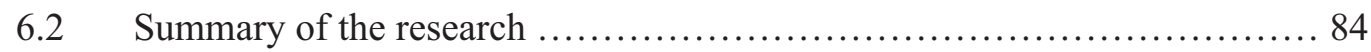

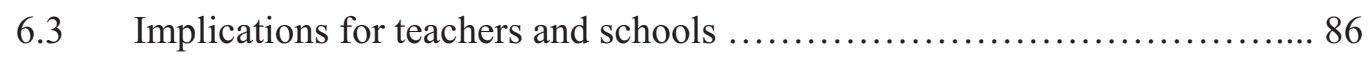

6.4 Recommendations for teachers, schools and policy makers ............. 88

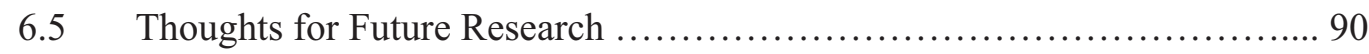


Appendix A: Parent Background Information

Appendix B: Talanoa Schedule for Parents

Appendix C: Talanoa Two Schedule for Parents

Appendix D: Parent Talanoa Summary Lists

Appendix E: Talanoa Schedule for Students

Appendix F: Information Sheet for School Principal

Appendix G: Consent Form for School Prinicipal

Appendix H: Information Sheet for Parents (English/Samoan versions)

Appendix I: Consent Form for Parents (English/Samoan versions)

Appendix J: Information Sheet for Students

Appendix K: Consent Form for Students 


\section{CHAPTER ONE： INTRODUCTION}

\subsection{Introduction}

Within New Zealand, Pasifika students' achievement and home-school partnerships are often identified as being at the forefront for those involved in primary school education. This thesis explores how knowledge of a group of Samoan parents' cultural reading practices can have the potential to empower teachers, schools and parents. As stated by Kay, Neher and Hall Lush (2010), communication with parents is effective when teachers listen "with respect, so stories and wisdom of families can be heard, acknowledged, responded to, and valued" (p. 417).

\subsection{Aim of the Research}

By investigating Samoan born parents' experiences and perceptions of home and school reading practices, the aim of this research is to add knowledge to teachers and schools' understandings of the social and cultural influences on learning to read. This can also be seen as a way to add value to school-home partnerships for these parents and their children. Through gaining greater understandings of Samoan parents' perceptions of home reading knowledge and practices, better connections may be able to be made that enhance engagement and achievement for Samoan students as well as inform current school literacy practice and pedagogy.

In order to achieve this it seems crucial for school to "create opportunities for parents to talk back to schools - and for schools to listen" (Dudley-Marling 2009, p. 1745). This acknowledges the importance of building dialogue and relationships between home and school sites in relation to reading practices. As suggested by McNaughton (1995) best practice involves knowledge and practices being jointly constructed with all involved being able to see the value in connecting the sites of home and school. As the education sector seeks to address the diversity and educational needs of Pasifika students, research like this aims to develop and enhance our knowledge of schoolhome interactions and partnerships. 
For this thesis and as a practising teacher, I am interested in exploring if there are common understandings between the groups involved - schools, students and parents in relation to reading practices at home and school. The parent and student Talanoa interviews are used to inform understandings of home and school reading practices. Talanoa is a talking methodology that allows for a less structured approach to interviewing and greater collaboration between the researcher and participants. The Talanoa sessions will be used to interpret the understandings and values that the parent participants hold and from a school perspective the current pedagogy that surrounds effective literacy practice is reviewed. There are clear directions and guidelines being promoted by the Ministry of Education at present to inform schools and teachers on the implementation of best practice (Ministry of Education, 2006; 2009). From these two sources, connections or disconnections are made between home and school practices for these Samoan parent participants.

\subsection{Significance of this topic}

It is argued that teachers and schools in New Zealand need to consider new ways to make better connections between home and school reading practices for our Pasifika students and parents (for example Cahill, 2006; Dickie, 2011; McNaughton, 2011). While many Pasifika parents want to be able to help their children and schools sometimes they may not know how to and feel their lack of experience with the New Zealand education system limits their participation in it (Fletcher et al., 2009; Cahill, 2006). This problem may be compounded as many schools and teachers do not know how to engage effectively with their Pasifika parents (ERO, 2008; Cahill, 2006; Gorinski \& Fraser, 2006).

A New Zealand snapshot of Pasifika student achievement in reading indicates that in major international and local assessments, Pasifika students are generally achieving at a lower rate than their European/Pakeha counterparts. The 2005/06 Progress in International Reading Literacy Study (PIRLS) (Ministry of Education, 2008) showed that $16 \%$ of year 5 Pasifika students did not reach the low international benchmark compared with $4 \%$ of European/Pakeha students. Only $40 \%$ of Pasifika students achieved reading scores equivalent to or above the PIRLS scale mean. 
The National Education Monitoring Project (NEMP), between 2004 and 2008, identified a small improvement in reading and speaking for year 4 Pasifika students but no improvement at year 8 (Ministry of Education, 2009). This evidence indicates that Pasifika students are under performing when compared to their European/Pakeha counterparts in reading. These achievement results for Pasifika students identify an issue for schools and educators involved in the primary school sector. In addition to the lower achievement results in primary schools for Pasifika students is likely to have a flow on effect to secondary and tertiary levels of education.

At all levels of education, the Ministry of Education and New Zealand Government have prioritised raising Pasifika achievement due to the over representation in statistics of lower achievement levels in literacy for Pasifika students. For these students and their families, the government is aiming to address this through the Pasifika Education Plan 2013-2017 (Ministry of Education, 2013). This government lead initiative has an identified vision of establishing an education system that "must work for Pasifika so they gain the knowledge and skills necessary to do well for themselves, their communities, Aotearoa New Zealand, the Pacific region and the world" (Ministry of Education, 2013).

One of the goals from the Pasifika Education Plan 2013-2017, which is pertinent to this research, is to increase engagement between Pasifika parents, families and schools in supporting student learning. This is a goal that has been a useful reference point, guiding the focus of using parent voice and exploring how our understandings regarding home-school reading practices can be strengthened. Another key goal identified in the Pasifika Education Plan is to promote closer alignment and compatibility between a learner's educational and their home and/or cultural environments (Ministry of Education, 2013). In order to achieve this there needs to be greater understanding between home and school practices and values. This thesis aims to add to our understandings of home reading practices through exploring the cultural experiences and beliefs shared by the Samoan participants involved.

The primary research question guiding this thesis is to identify how the cultural values and experiences of Samoan parents influence the home reading practices they use with 
their own children. From this the connections and disconnections between school and home reading practices for these Samoan parents are drawn and discussed.

\subsection{Overview of Thesis chapters}

The structure of this research thesis is outlined below;

\section{Chapter One: Introduction}

Chapter One has introduced the aim and the significance of this research. The central aim is to enhance teachers' and schools' understandings of the home reading practices used by a small number of Samoan parents in one community within New Zealand. By investigating this connections and disconnections between school practice and home can be made.

\section{Chapter Two: Literature Review}

Chapter Two, through the lens of socio-cultural theory looks at literacy learning. The review then identifies recent research on home and school reading practices through literacy as social practice. Samoan and New Zealand literacy are discussed to help identify and understand the key differences between the two practices. The area of home-school partnership is discussed along with current research views and findings on Pasifika education within the primary school sector.

\section{Chapter Three: Methodology}

Chapter Three outlines the research methodology and procedures used. This research takes a qualitative case study approach that incorporates a socio-cultural perspective primarily through the use of Rogoff's three planes of analysis (1995) and the guiding principles of Pasifika methodology through the Pasifika Education Research Guidelines (Anae et al., 2001). The research questions, setting and the participants along with the ethical considerations are presented. 
Chapters Four and Five combine the findings and discussion for the two different contexts used, Samoa and New Zealand. Chapter four outlines the Samoan parent participants' responses during the Talanoa sessions regarding their memories and experiences of learning to read. The three literacy sites of the Pastor's house, primary school and house are used to explore and discuss the reading practices employed in Samoa when the adult participants as children were learning to read. In both Chapters four and five, Rogoff's three planes of analysis (1995) are used to explore and discuss the impact and influence of social and cultural reading practices and interactions.

Chapter Five: Findings and Discussion - A New Zealand Context

Chapter five establishes what home reading the participants are using with their own children in New Zealand. The responses from the child participants are incorporated to provide further evidence of home reading strategies and practices. The parent participants' knowledge of school reading practices in New Zealand is also discussed.

\section{Chapter Six: Conclusions and Recommendations}

In chapter six the research findings are summarised. Implications and recommendations are given for teachers and schools within New Zealand's primary school sector. Connections are also made to the Pasifika Education Plan 2013-2017 (Ministry of Education, 2013) in order to show the relevance and value of this thesis in the current education climate. 
CHAPTER TWO: LITERATURE REVIEW

\subsection{Introduction}

The chapter begins with an overview of socio-cultural theory (Au, 2003; Luke \& Freebody, 1997; Street, 1997) in order to outline the theoretical framework within which this thesis is based. This theory allows the social and cultural influences that home reading practices have on individuals to be explored and discuss how these might connect or disconnect with school practices. A socio-cultural perspective enables literacy to be seen as social practice, where individuals' cultural and social backgrounds and values play a role in literacy acquisition. Rogoff's planes of analysis (1995) framework have been used to support and interpret the findings and are therefore outlined in this chapter.

The role that school and home literacies play in literacy acquisition and how these differ for different cultural groups is then explored with a focus on literacy teaching in both New Zealand and Samoa. The chapter then reviews the literature on the importance of home-school partnerships in general then into recent Pasifika educational research regarding literacy and home-school practices within New Zealand.

\subsection{Literacy learning}

The interpretations of literacy acquisition are wide and varied so when reviewing the literature for this research, the guiding principle applied was that literacy is more than a set of skills (Street, 1997). If literacy acquisition is seen not solely as a set of skills then it is a process that draws on a student's own experiences of literacy and the practices of reading and writing. If literacy is linked to experiences, social and cultural identities become important factors for acquisition (Street, 1997; Luke \& Freebody, 1997; Nieto, 2010). Contrasting this, if literacy is seen as just as a universal technical skill, then teachers and schools are able treat it as the only kind and teach one set form (Street, 1997). 
While literacy being viewed as an acquired skill set is identified, the major focus for this thesis is how literacy learning is strongly tied to the social and cultural influences and role this plays in home and school literacies.

\subsection{Literacy as social practice}

Literacy acquisition is not a single identity, as there are multiple ways to use and make meaning. The notion being that one size can't fit all individuals and that the social and cultural values individuals bring to reading practices have an impact on acquisition. So in order to address the differing learning needs of students, teachers and schools have to be able to "take account of the variation in literacy practices amongst students and give value to their different backgrounds and the different literacies they employ in their home contexts" (Street, 1997 p.54). Literacy as social practice is described by Street (1997) as an 'autonomous' model of literacy. Street goes further by using an 'ideological' model of literacy, where literacy acquisition is not only varied due to social and cultural influences but power relations as well. Literacy always involves "contests over meanings, definitions and boundaries and struggles for control of the literacy agenda" (p. 48).

Pahl and Rowsell (2005) argue that literacy is tied to students' cultural backgrounds therefore the languages, values and beliefs that students gain from their backgrounds are used to make meaning and gain identity. "Our students carry around tool kits which make up who they are and literacy is tied into that" (Pahl \& Roswell, 2005, p. $5)$.

Socio-cultural theorists state that students have to be able to move across different contexts, noting that how students use language at home is different from school. Teachers need to be able to build on and access their students' home language and literacy by getting the balance right between school and home literacies through making connections and utilising a student's prior experiences out of school. The ways teachers and schools bring their students' literacy practices into the classroom is critical, in order to develop a more rich and inclusive curriculum as well as active engagement for all students regardless of social or cultural background. Pahl and Roswell (2005) link this to cultural identity stating that by "giving our students' 
literacy practices recognition within classrooms, we let in identities" (p. 2).

By applying a socio-cultural perspective, literacy is viewed as happening in different social and cultural contexts. Students bring their understandings to these contexts based on their own social and cultural backgrounds (McNaughton, 2002; Nieto, 2010). Literacy knowledge is tied to students' cultural and social identity - "the languages, values and beliefs that students bring to make meaning and gain identity for themselves" (Pahl \& Roswell, 2005, p. 5). "From a sociocultural perspective, every individual possesses a wealth of knowledge that is critical to his or her existence within his or her cultural community. In order for individuals to construct new meanings, those pre-existing knowledge bases and experiences need to first be recognized, valued as legitimate, and then extended in new ways and in new directions" (Hamel, 2003, p. 11).

When literacy is viewed as social and cultural practice rather than a set of transferable and neutral skills, literacy learning cannot be solely connected to school literacy (Street, 2007). This interpretation values and utilizes the meaningful literacy practices within families and communities. Using this interpretation allows for the acknowledgement of the mismatches or disconnections that can be created for a student whose cultural or social identity does not fit into the school model of literacy. At times, disconnections do exist between home and school reading experiences for students who do not fit into the dominant culture of society (Duke \& Purcell-Gates, 2003; Nichols \& Cormack, 2009; Dudley-Marling, 2009). For these students this may lead to disengagement in learning as they are more likely to experience difficulties with making connections between home and school practices.

A problem may occur when students' literacy knowledge is different from the established school literacy and often valued less by teachers and schools (Luke \& Freebody, 1997; Street, 2007). Teachers and school structures tend to value the 'cultural capital' of the dominant culture(s). The theory of 'cultural capital' originated from Bourdieu (as cited in Dudley-Marling, 2009). A defining element of cultural capital is "that students from socially and culturally dominant groups generally begin school with the kind of knowledge that will place them at an advantage to learn in that setting" (Nieto, 2010, p.38). When this occurs literacy practice is seen as not neutral 
and students are not all on a "level playing field" in relation to access to school resources and knowledge (Luke \& Freebody, 1997, p. 3). This notion of 'literate cultural capital' for socio-cultural theorists is linked to home access and interactions with literacy resources and parental attitudes towards reading.

Socio-cultural theorists (Dudley-Marling, 2009; Hamel, 2003; Heath, 1983; Nieto, 2010) argue that if literacy learning is to be seen on a more equal footing then school literacy needs to be viewed as only on type of literacy that can be very different from other literacy types that naturally occur in homes and communities. These differences need to be acknowledged and valued. A key point to be made here is that "the language and literacy experiences that each child brings to the classroom are all valid and important within their own cultural communities" (Hamel, 2003, p.20).

When these differences are not acknowledged mismatches between home and school literacies are created that could contribute towards literacy difficulties in early schooling (Duke and Purcell-Gates, 2003). If teachers and schools do not make links to home literacies then transfer of knowledge is limited across different sites (Duke \& Purcell, 2003). Teachers and schools need to recognise students' home language and literacy experiences as real learning and find ways to link these experiences, to the new experiences the students will encounter in the classroom (Heath, 1983; LadsonBillings, 1994). It is important to question what literacy connections are students able to make if their home and school practices are vastly different. How teachers and schools acknowledge, understand and utilise home literacy practices is critical for literacy acquisition.

\subsubsection{Rogoff's planes of analysis}

Rogoff's three planes of analysis (1995) that are based within socio-cultural theory provide an analytical framework that is appropriate to use within this qualitative research to aid in analysing the research findings. The planes of analysis allow a researcher to explore the nature of learning and how social interactions are embedded within cultural communities. These social interactions involve individuals co- 
constructing meaning with each other and run through the three identified interconnecting planes.

Rogoff's planes (1995) are defined as participatory appropriation (at the personal level), guided participation (at the interpersonal level) and apprenticeship (at the community/institutional level) and do not sit in isolation from one another, therefore making the individual and environment interdependent. For the purpose of this research, the planes are used to help explore and interpret patterns of socio-cultural activity that the participants were involved in when learning to read as children.

The personal plane shows the individual on their own and is referred to as participatory appropriation. This is the personal process through which individuals engage in culturally organised activity. The "process by which individuals transform their understanding of and responsibility for activities through their own participation" (Rogoff, 1995, p. 150). An individual is able to make changes and be involved in further similar activities. Participation involves efforts to understand and contribute to social activity. The interpersonal plane shows the social influence of others on an activity and is termed guided participation. Here 'guided' refers to the interpersonal involvement between people as they participate and communicate in culturally organised activity and the direction offered by cultural and social values. Participation is defined as observation as well as the hands-on involvement in the set activity (p. 142). The third plane is labelled community/institutional and relates to the cultural influences on an activity. This apprenticeship involves individuals participating with others in culturally organised activity; "the cultural practices of the activities they contribute to or in" (p. 143).

\subsection{A view of School Literacy}

It is important to acknowledge that much has been written about the debates and methods around best literacy practice in relation to reading instruction (for example McNaughton, 2002; Tunmer, Chapman \& Prochnow, 2004). The reading debate can be linked back to two paths - a code-based or meaning-emphasis approach. It is important to note that one does not completely exclude the other but for the purpose of reviewing school literacy in general terms, the basic principles behind both 
approaches have been outlined. It is also important for this thesis to distinguish between the two, as current New Zealand practice aligns more closely with a meaning-emphasis approach where as Samoan literacy with a code-based one.

A code-based approach emphasise sounding out words, reading new words in isolation and the importance of accuracy of when reading words within sentences. Oral reading is also a strong component of the code-based approach. As cited by Rassool (1999) cognitive theorists take a more scientific approach to literacy, where outcomes are measured in terms of skill acquisition. It is cognitive processes that underlie learning how to read rather than social or cultural processes; "teaching literacy is teaching the skills of reading and writing" (p. 27). Gough (1995) states that literacy is a 'single thing' and that when assessing literacy acquisition social and cultural factors can be extracted out (cited in Rassool, 1999). Theorists (For example, Nicholson, 2003; Greaney, 2003) using this approach to argue that while sociocultural theory acknowledge the importance of home-school relationships they fail to consider the explicit phonological-based skills that are needed in the teaching of reading (cited in Openshaw, 2004).

The alternative is a meaning-emphasis approach that places greater emphasis on whole word reading, reading new words in context and maintaining the flow of reading. Another way of discussing these approaches is outlined by Bruning, Schraw and Ronning (1999). Here the terms used to discuss the different approaches to reading comprehension are "data-driven, conceptually driven and interactive" (p. 264). A data driven approach focuses on decoding and word meaning, where information starts from letters or words and then moves into making meaning. In contrast, the role of knowledge is emphasised in a conceptually driven approach. When reading an individual will use their expectations about the text and prior knowledge to aid meaning. The third approach, interactive, combines both data-driven and conceptually driven, as a way to address the limitations of both. Here reading comprehension is identified as a combination of both approaches.

For this research, school reading practices within a New Zealand context have been defined as current effective pedagogy and practices regarding literacy teaching. The current Ministry of Education's literacy guidelines and initiatives, found in teacher 
support materials including the Literacy Learning Progressions (2010), English Language Learning Progressions (2008) and Effective Literacy Practice Years 5-8 Handbook (2006), use a meaning-emphasis approach to reading, where learning is not separated from context and is based on the building of meaning from texts. A key message here is that literacy learning is socially constructed.

The Ministry of Education's Effective Literacy Practice Years 5-8 Handbook (2006) defines literacy as "the ability to understand, respond to, and use those forms of written language that are required by society and valued by individuals and communities" (p. 8). Literacy acquisition is seen to have three aspects; learning the code, making meaning and thinking critically (Ministry of Education, 2006). 'Learning the code' involves decoding and encoding through learning the conventions of written language and the skills required to read and write letters, words, and text. 'Making meaning' involves comprehending a text through using a range of self monitoring strategies and 'thinking critically' is thinking beyond a literal level.

The alternative code-based approach places greater emphasis on phonics and phonological awareness. Tunmer, Chapman and Prochnow (2004) argue that students who come from poorer home literacy environments require a more phonological approach to learning to read. More explicit teaching of phonics would allow these students to be able to focus 'solely on letter-sound patterns in isolation' and "learn word decoding that may be useful in all text not just a specific text” (p. 139). A key point to consider here is that the code-based approach to reading acquisition seems to align most closely to the cultural values and practices being used by Pasifika communities within New Zealand as is discussed later in this chapter when reviewing at Samoan literacy.

McNaughton (2002) claims that teachers need to be able to make explicit links for students between their knowledge of letters and sounds into knowledge of text, in reading and writing. This balance allows for text free and text-connected teaching, therefore learning opportunities in both phonics in isolation and incorporation into meaningful text.

So it could be argued that there are still mixed messages regarding literacy instruction for New Zealand teachers and schools. Added into this mix is the impact that 
Reading and Writing Standards for Years 1-8 (Ministry of Education, 2009) will have in relation to literacy pedagogy and practice within New Zealand. Since National Standards were introduced in 2009, there has been ongoing criticism and concern around their anticipated role in the narrowing of the curriculum and therefore practice by the teaching profession. In addition, the Standards strong focus on assessment is likely to lead to a 'high-stakes assessment' system (Thrupp, 2013).

\subsection{School reading practices in a New Zealand context}

In New Zealand, reading practices emphasise the importance of decoding, making meaning and thinking critically (Ministry of Education, 2009). The following instructional approaches to teaching reading are used;

The practice of reading aloud to students, involves students not having to focus on decoding but being active and immersed as they listen to the teacher reading a selected text. Students are able to create meaning by making connections as they develop new knowledge (Ministry of Education, 2006). In a guided reading session, a teacher is working with a small group of students who have a similar instructional need. Each student has a copy of the text and with teacher support develops the reading skills of decoding, making meaning and thinking critically. Shared reading allows for interaction as the teacher and student read the selected text together. All students are able to see the text and actively engaged with it. This approach is supportive in nature and enables students to develop their strategies and knowledge for how texts work. Through independent reading, opportunities are given for students to read a wide range of text for interest and enjoyment, as well as allow students time to practise reading strategies (Ministry of Education, 2006).

\subsection{Reading practices in a Samoan context}

When considering the literacy practices that are valued and employed by Samoan communities within New Zealand, it is important to be aware of the historical context of literacy development in Samoa. Samoa has a strong oral literacy base with no 
written form used until the arrival of the European missionaries in the 1830s. The first Samoan books were printed in 1834 along with the translation of the Bible into Samoan so it could be read and studied (Tuafuti, 2000).

Christianity was spread throughout Samoa by missionaries, through the village church, the home of the pastor or by missionary established educational institutions. Pastors' schools were an important development in Samoan literacy. The process of reading and writing started with the Samoan alphabet, the letters $A$ to $\mathrm{V}$, with the missionaries introducing the letters $\mathrm{H}, \mathrm{K}$ and $\mathrm{R}$ (Tuafuti, 2000). There was a strong emphasis on oral language, with memorisation and performance being highly valued. Church was seen as an important site for literacy acquisition and practice (Duranti, Ochs \& Ta'ase 2004).

Within Samoan society the Pastor's role in teaching and learning was seen as a key component for early literacy acquisition. Historically, the Pastor at church or within his house would hold reading lessons based around the Bible throughout the week. There would be a strong emphasis on oral language, with memorisation and performance being highly valued. Literacy learning was strongly linked with Christianity. Ferguson, Gorinski, Wendt Samu and Mara (2008), cite Meleisea (1987) who writes, "the Pastors and their wives ran schools for both children and adults in villages through the nineteenth century and up until the 1950s most Samoans were educated by village pastors" (p. 31).

Bible reading involved learning through recitation using a performance style (McNaughton, Amitanai-Toloa \& Wolfgramm-Foliaki, 2009). The tauloto ${ }^{1}$ (performance) routine as an oral pattern of learning that was used both at the Pastors' house and church, involving a model being given orally by the teacher or adult with the child responding to or imitating (Tagoilelagi, 1995). This oral reading of the Bible and interpreting of bible passages, involves the strategies of imitating, memorizing and reciting. The primary literacy focus within the pastor's school was on reading the bible and writing stories that were dictated from the Bible (Tuafuti, 2000). This is seen as the traditional way of learning the Bible, which has been handed down through generations and it is identified as a historical practice by Samoan

\footnotetext{
${ }^{1}$ Tauloto - word definition in English 'speech'
} 
communities. The Bible holds an authoritative position in the morals and beliefs of Samoan people and therefore has strong cultural values connected to it (Duranti, Ochs \& Ta'ase 2004; Tagoilelagi, 1995).

In Samoa, it was common practice for children aged 1 to 5 years to participate in literacy lessons at the Pastor's school/house, and then after the age of five the lessons would be held after school. For many Samoan children, lessons with the pastor would continue until their early teens (Duranti and Ochs, 1993). Samoan children would learn to read and memorise the Pi Tautau (Samoan alphabet) chart. At an early age, only verbal responses were expected, as the children would learn to respond orally and often imitate what the teacher was saying aloud. As the children got older they would learn to memorise and recite a phrase or sentence from the Bible with the Pastor questioning what they had read (Tagoilelagi, 1995). The Pastors' schools would also have examinations and/or competitions based on Bible stories.

Tuafuti (2000) notes that the literacy skills taught at the Pastors' schools are extended and reinforced in state schools and that "school related literacy programmes shared the same values and language functions as those seen in the community" (p.11). Reading at school and Sunday school was not always a very interactive process, as students were expected to sit quietly and listen to the reader (McNaughton, AmitanaiToloa \& Wolfgramm-Foliaki, 2009).

It is evident that this more code-based approach to literacy relies less on making meaning and is often defined as a more traditional method of teaching reading. The emphasis is on sounding out, phonological awareness, pronunciation of common spelling patterns and retrieving words from memory (Tunmer, Chapman and Prochnow, 2004) and a more data-driven approach to reading comprehension (Bruning, Schraw and Ronning, 1999).

An alternative approach to this is based on the notion that what is learnt cannot be separated from the context, it is about how meaning is constructed from texts. This meaning-emphasis approach relies on children learning through reading, being read to and being immersed in a literacy-rich environment. Again it is interesting to note that in New Zealand, the current Ministry of Education's literacy guidelines and 
initiatives, use a meaning-emphasis approach to reading, where learning is not separated from context and is based on the building of meaning from texts.

It is therefore important to acknowledge that the traditional reading practices in Samoa, are different from how reading practices in New Zealand would be defined. Another important component to note within Samoan literacy is that these traditional practices are constructed from social and cultural beliefs as noted by Tuafuti (2000) "Samoans use literacy for biblical, moral and cultural instruction and for transmitting information that reveals and supports Samoan beliefs and values" (p.11). Tuafuti (2000) adds to this by stating that; "for some cultures, literacy is about reading, writing, and promoting abstract thought, rationality and critical thinking. To others, it is about oral language, memorisation, and transmission of beliefs and values that enlighten the knowledge of heritage and ethics" (p.10).

\subsection{A view of Home Literacy}

A socio-cultural approach recognises that school literacy may differ from the kinds of literacies that children may experience in their homes and communities. Hence seeing how school and home contexts engage or do not with each other is critical (Gregory, 2007; Nichols \& Cormack, 2009). Students' ability to make connections between their known home literacy experiences and new knowledge is critical for literacy learning and acquisition. Many socio-cultural theorists argue that it is important to view home literacy in a positive light rather than seeing contrasting home literacy practices with schools as being a disadvantage to students (Gregory, 2007; Kay, Neher \& Lush, 2010; Conteh \& Kawashima, 2008). Conteh and Kawashima (2008) make the point made that 'teachers themselves need to be informed of the rich and diverse ways in which children from different backgrounds can learn at home and in the community' (p. 114). This view is reflected in current Ministry of Education publications, such as the Effective Literacy Practice Years 5-8 handbook (2006), where teachers are asked to see diversity as a rich resource rather than a difficulty.

As noted by Heath (1983) the language and literacy experiences found in some students' homes are very different from the language and literacy experiences they are 
expected to participate in school. Heath's work (1983) identifying the different types of literacy observed in three different North American communities is often cited when discussing the impact of home reading practices on school literacy acquisition. It is research that provides an example of how different community groups interpret and practice home reading strategies based on their own cultural values and beliefs, where "each community has rules for socially interacting and sharing knowledge in literacy events" (Heath, p. 50).

The home reading patterns in each community were different with one aligning closely with school based practices. Within the white, middle class community, the children were being exposed to reading patterns that aligned with school practices through their interactions with books. These children were being given opportunities that allowed them to practise the literacy skills see as school appropriate, learning how to take meaning from books and also how to talk about what they had read. This pattern was found in classroom interactions when learning to read.

In contrast to this the children from either the white working class or black working class communities were experiencing different types of home literacy. Within the black working class community there were limited opportunities to read books except Sunday school materials. Oral language through story telling was used. For the children from the white working class homes rote learning and repetition were the key reading strategies being used. Often the book content was not discussed in depth and there were limited chances to apply new knowledge to other contexts. The value of Heath's (1983) study is to illustrate the difficulties for both of these groups of children once they started learning to read at school.

These differences in how communities value and use home reading strategies and practices need to be acknowledged and better understood when considering homeschool connections and knowledge of school practices. Therefore "in some communities these ways of schools and institutions are very similar to the ways learned at home, in other communities the ways of school are merely an overlay on the home-taught ways and may be in conflict with them" (Heath, 1983, p.50). 
Gregory's (1999) work exploring home literacy practices views home literacy in a positive light arguing that rather than seeing contrasting home literacy practices with school as being a disadvantage, it can be seen as a strength. Gregory cites a number of different studies that have shown the wealth of literacy practices in low-income families. Gregory acknowledges that the importance of family in literacy development is recognized but not in a diverse way, in a 'right' way. If family practices fell outside of this deemed right way they have tended to remain invisible to both school and government.

Gregory (2007) makes a strong challenge for not using deficit thinking around home backgrounds, ethnicity and low socio-economic status, aiming to show the power teachers and schools have in how they elect to understand and utilise students' varying literacies, seeking to use "contrasting but complementary literacies" (p. 44). Street (2004) also argues for 'making visible the complexity of local, everyday, community literacy practices and how they might be built upon in educational contexts (p. 129).

It is important to recognise that there are mixed interpretations for how home literacy practices can be seen to complement or contrast with school practices. It is very clear that if home literacy practices are to be acknowledged and valued, how schools engage with their parents and local communities to activate this knowledge is critical.

\subsection{Home/School Relationships}

When viewing home and school literacy practices it is essential not to develop a deficit model of thinking. This is particularly the case when children are identified as not achieving at the expected level for their age cohort. When a deficit model is used the blame is often placed on students' families and communities (and culture) for underachievement at school (Dudley-Marling, 2009; Hamel, 2003; Nichols \& Cormack, 2009). By using a deficit model of thinking the issues surrounding student learning are seen to come from out-of-school factors and this creates a problem as it potentially allows schools to become disengaged in terms of the impact they can have on student achievement (Dudley-Marling, 2009; Nichols \& Cormack, 2009). 
In general terms the expectations for home are based on the school's way of doing things. This involves putting school literacy practices into the home rather than using a joint collaborative approach that takes into account the knowledge that can be gained from understanding the role and value of home literacy practices on learning and achievement. This "one-way model of involvement" that is often being used by schools means that parent knowledge and voice may be lost (Conteh \& Kawashima, 2008 , p. 113). It is a limited view that is not able to recognize fairly the range of ways that parents and families support learning at home (Dudley-Marling, 2009).

In order to move away from the identified 'one-way model of involvement' (Conteh \& Kawashima, 2008) where schools are advising parents about how school-home literacy practices and expectations could or should look, an alternative method can be used. McNaughton (2001) labels this alternative method 'co-constructing expertise' (p. 40). This is a more useful approach to take as co-constructing allows teachers and parents to develop together shared understandings about teaching, learning and literacy. It is argued that educators in New Zealand need to consider new ways to make better connections between home and school reading practices for our Pasifika students and parents (Cahill, 2006; Dickie, 2011; McNaughton, 2011). Many Pasifika parents want to be able to help their children and schools but sometimes do not know how to do this and feel their lack of experience with the New Zealand education system limits their participation in it (Fletcher et al., 2009; Cahill, 2006). In addition, many schools and teachers do not know how to engage effectively with their Pasifika parents (ERO, 2008; Cahill, 2006; Gorinski \& Fraser, 2006).

Gorinski and Fraser (2006) identified a lack of New Zealand based research in the area of home-school relationships. It was noted that there is awareness from teachers and schools around the importance of understanding students' home backgrounds but that there are problems with acting on it. This again shows that theory may not always fit with practice when addressing possible mismatches or disconnections for Pasifika students and their parents when participating in school learning environments.

In New Zealand discussions around strengthening home and school partnerships are often held. Effective home-school partnerships are identified as being a key way to engage with parents, families and communities which in turn leads to better 
educational outcomes for students. Biddulph, Biddulph and Biddulph (2003) state that establishing strong home and school connections are the most effective way for schools to understand the needs of their diverse learners.

These research findings align with what other researchers have discovered when looking at schooling and Pasifika parents (Cahill 1996; McNaughton, 1995; Tufulasi Taleni et al, 2007). International studies have also shown that there are clear differences between home and school practices for different cultural groups who are not in middle class white demographic, where cultural capital is generally aligned more closely with the schools (Crozier, 2000; Dudley-Marling, 2009; Heath, 1983). It is clear that students need to be able to maintain their cultural identities and teachers need to be able to help students recognise and value diversity (Nakhid, 2003).

\subsection{Looking at Pasifika/School Partnerships}

Within New Zealand Pasifika research, cultural identity has been recognised as a key element for supporting Pasifika students' achievement in literacy (Cahill 2006; Fletcher, Parkhill, Fa'afoi, Tufulasi Taleni \& O’Regan 2009; Gorinski \& Fraser, 2006). Fletcher et al. (2009) note that there was recognition by their participating schools that building students' first language and integration of culture into classrooms plays a key role in confidence and identity, citing some examples of teachers tapping into what their students bring into the classroom and finding ways to bridge the gaps between home and school literacies.

In contrast to this, Cahill (2006) states, "few New Zealand teachers have an in-depth knowledge of the values inherent in Samoan society and culture" (p.69). Similarly, McNaughton (2002) challenges what teachers really know about their culturally diverse students, arguing that teachers need to have a better knowledge of what literacy skills these students are bringing to the classroom. Biddulph, Biddulph and Biddulph (2003) also cite McNaughton when arguing that teachers and schools need increased knowledge of cultural literacy practices and experiences because without this they are less able to identify the relevant knowledge and use this into text reading and writing school activities. So acknowledging cultural identity is important but 
establishing ways to value and integrate strategies to promote it within classroom and school practices appears to be challenging for many teachers. This type of research reaffirms that teachers and schools often have an awareness of the importance of cultural identity and making connections for students but may not always be confident to act or are being provided with enough guidance in this area.

Gorinski and Fraser's (2006) review on effective engagement of Pasifika parents also points to the role teachers and schools have in needing to understand students' cultural contexts to be able to foster effective learning relationships. That cultural context is interconnected with literacy acquisition for the students.

But there is another crucial element to be considered. If home-school partnerships are truly to be equal and meaningful for all involved then knowledge needs to be shared in both directions. There needs to be a significant shift from solely implementing school practices into homes to what home values and knowledge can be adapted in order to make better connections for students from all cultural backgrounds into school. There is a need to develop a shared understanding of what effective homeschool partnerships in education look like in terms of practice (Gorinski \& Fraser, 2006, p.2).

There are clear, on-going guidelines from the Ministry of Education (2007) in New Zealand directing schools to develop effective home-school partnerships. A number of initiatives have been developed to help support schools with this, including the Pacific Island School Community Parent Liaison (PISCPL) project, Reading Together programme and Pause, Prompt and Praise: reading tutoring (cited in Gorinski \& Fraser, 2006). These initiatives have shown to be effective in supporting parent engagement and home-school connections and have focused primarily on implementing school practice into the home.

Within New Zealand, reviews on the experiences of Pasifika students and their communities have been undertaken with areas identified for further research. One key area is around building positive and productive partnerships between home and school. Alton-Lee (2003) through the Best Synthesis Synthesis (BES) framework, has recognised that ways to facilitate effective links between school, home and other 
culturally significant contexts for learners need to be established. Underpinning BES (Alton-Lee, 2003) is the key understanding that culture and identities are relevant to effective teaching and learning as well as a commitment to fostering relationships with families and communities.

Another area is teacher responsiveness to the knowledge and experiences Pasifika students bring to school, identifying that teacher practices and home-school partnerships have the greatest influence on student educational outcomes (Ferguson, Gorinski, Wendt-Samu \& Mara, 2008, p. 49). Other researchers have also advocated for greater co-construction between home and school sites. For example Ferguson, Gorinski, Wendt-Samu and Manu (2008) write "when schools, parents and communities work effectively together to provide education that best supports the strengths, needs and aspirations of students" (p. 35). It is also noted by Ferguson, Gorinski, Wendt-Samu and Manu that for true co-construction to work there needs to be equal input from all involved but that for Pasifika parents their could be cultural constraints around how teachers and school seen.

The Best Evidence Synthesis (Biddulph, Biddulph \& Biddulph, 2003), considered the community and family influences on children's achievement and the practices that worked best were programmes that allowed for constructive home-school partnerships through strong home-school links and empowering parents by respecting their dignity and cultural values as well as aiding understandings of how to help their children educationally through the use of community resources, contexts and experiences. It was identified that within communities there are the resources and experiences to support achievement but that overseas research shows that this is not always recognised by schools.

The latest key initiative involving Pasifika education and achievement is the Ministry of Education's Pasifika Education Plan 2013-2017. Clear goals and targets have been set involving all sectors of education. For the primary sector a key target is to have $85 \%$ of year 1-10 Pasifika learners meeting literacy and numeracy expectations, including achieving at or above in National Standards by 2017. Linked to this is the goal for "closer alignment the learner's educational environment and their home 
and/or cultural environment, so that communities, education providers and services, are using their individual, collective and cultural connections and affiliations to work together towards better outcomes and better results" (Ministry of Education, 2013).

\subsection{Positioning this research thesis}

For this thesis, the researcher's interest and aim was to explore if there are shared understandings between the groups involved in learning and achievement for Samoan students - schools, the students and their parents in relation to knowledge around reading practices at home and school. From a school perspective, the current pedagogy that surrounds good effective literacy practice has been reviewed earlier in this chapter to provide a background to school reading practices. The directions and guidelines being promoted by the Ministry of Education at present are used to inform teachers and schools on the implementation of best practice.

By investigating parent and student perceptions and experiences of reading knowledge and practices, the aim is to add value to school-home partnerships through a focus on learning between parents, schools and teachers to enhance student achievement. Through gaining greater understandings of what Samoan parents' perceptions of home reading knowledge and practices are, better connections may be able to be made between home and school that enhance engagement and achievement for Samoan students as well as inform current school literacy practice and pedagogy.

It seems crucial for school to 'create opportunities for parents to talk back to schools and for schools to listen' (Dudley-Marling 2009, p. 1745). This acknowledges the importance of building dialogue and relationships between home and school worlds in

relation to reading practices. Schools have a responsibility to connect the literacies of home and school (McNaughton, 1995). 


\section{CHAPTER THREE: METHODOLOGY}

\subsection{Introduction}

In this chapter the research methodology and procedures used are outlined. The chapter starts with the research questions to be investigated and then provides information on participant and site selection, data collection and analysis methods used as well as the ethical considerations and limitations encountered during this research.

\subsection{Research questions}

The Primary Question is;

How do the cultural values and experiences of Samoan parents influence the home reading practices they employ with their children in New Zealand?

The Secondary Questions are;

What home reading practices are being used?

What are their children's experiences of home reading practices?

What knowledge of New Zealand school reading practices is evident?

\subsection{The Theoretical Framework}

The primary purpose of this qualitative case study research was to explore Samoan parents and their children's experiences and perceptions of learning to read and the role this plays in home reading practices. For the parent participants two areas were explored; their experiences of learning to read as children in Samoa, the influence of this on home reading practices with their own children and their knowledge of school practices in New Zealand. The student participants' responses relate to their home reading experiences in New Zealand. From this information the aim was to examine 
whether there are connections or disconnections between home and school reading practices for these parents and their children in a New Zealand context.

Qualitative research is based on the assumption that individuals living and interacting within their own social worlds construct 'a reality' (Creswell, 2003). A qualitative researcher's main interest is to understanding how people construct meaning from their life experiences and make sense of the world that they live in. By using a small number of participants a rich description is formed that allows the researcher to form a detailed picture of the social and cultural values and influences within a specific group or community. Creswell (2003) argues that the construction of meaning is shaped in part by the cultural values and beliefs in which people encounter within their communities. It is a form of interpretative inquiry, where the researcher makes an interpretation of what they see, hear and understand.

A qualitative approach was used in order to compare the participants' experiences in depth. The focus was to explore the participants' experiences to gain insights into the cultural values and practices that have helped form and impact on the home reading practices they employ. The evidence came from what the participants recalled and interpreted about their reading experiences and actions both in Samoa as children and now as adults with their own children in New Zealand.

Within the realms of qualitative research, a case study structure was selected to allow for in-depth understandings of a specific case within a real life, contemporary setting. A case study enables the researcher "to illustrate an issue, and compile a detailed description of the setting for the case" (Creswell, 2013, p.102). Research shows that cultural values vary between communities and there is often a disconnection between home and school practice for cultural groups that are not defined as white middle class (McNaughton, 1995; Heath, 1983; Au, 2011). This research aims to add further evidence to this by providing insights into how the cultural childhood experiences of learning to read in Samoa have influenced and shaped the home practices being employed. In addition to this the parent participants' knowledge of school reading practices in New Zealand is examined and used to further develop the notion of the disconnections between home and school practices. 
A case study's focus is on holistic description and explanation (Merriam, 1998). It is defined as research that "provides a detailed account and analysis of one or more cases" (Johnson \& Christensen, 2012). By reviewing in depth the experiences of learning to read in Samoa as well as the thoughts and ideas around home and school reading practices in New Zealand for the research participants, a picture emerges of the cultural beliefs and actions that are being employed. From this conclusions can then be drawn to see if there are connections or disconnections regarding reading practices.

It is also important to note here that a sociocultural perspective has been used to inform and guide the analysis of this research. Here literacy is seen as "a set of social and cultural practices that involve specific ways of interacting with people, specific ways of using language, specific sets of values for various kinds of behaviour, and specific sets of interpretations for understanding and guiding behaviour" (DudleyMarling, 2009). The value of using a sociocultural perspective is that it allows for home literacy practices and experiences not to be seen in a deficit mode but as practices to valued and better understood to enhance home and school connections. This is a vital intention of this research, to promote an informed awareness of the social and cultural values that help shape the home reading practices of Samoan parents and their children is of value to all educators. "Teachers themselves need to be informed of the rich and diverse ways in which children from different backgrounds can learn at home and in the community" (Conteh \& Kawashima, 2008, p. 114). It needs to be acknowledged that there are different cultural values at play and that children's learning opportunities are structured differently but that "understanding different cultural practices does not require determining which one is 'right', we can be open to possibilities that do not necessarily exclude each other" (Rogoff, 2003, p. $368)$.

Rogoff's three planes of analysis (1995), which were outlined in Chapter Two, are used to explore the participants' acquisition of reading skills through their participation in various social and cultural activities. Using Rogoff's notion of guided participation enhances this further. Guided participation is defined as a way "to help us focus on the varied ways that children learn as they participate in and are guided by the values and practices of their cultural communities" (Rogoff, 2013, p. 284). 


\subsection{Pasifika Research Methodology}

The methodology used for this research has been guided by the Pasifika Methodology principles. The Pasifika Education Research Guidelines (Anae, Coxon, Mara, WendtSamu, \& Finau, 2001) set out clear strategies to ensure that Pasifika values and beliefs underpin research that involves Pasifika people as participants.

Ownership and consultation throughout the research process is recommended by creating opportunities for the sharing of purposes and goals by and for participants. Another key strategy is to provide insights into the uniqueness and reality for Pasifika people (Anae et al., 2001). This involves incorporating key Pasifika beliefs and values into the methodology being used. The key Pasifika values that have been included in this research are verbal negotiation rather than written, perceptions of 'time' and the notion that church and culture are inseparable. These strategies have been used where possible to guide this research and the processes used have been outlined below.

For myself as a Pakeha researcher, one way to support this has been through consultation with a Samoan advisor. Initial contact was made with a Samoan support person, who is an experienced teacher and teacher educator at Victoria University. Appropriate ways to approach and engage with Pasifika participants were discussed. It was advised that a direct face-to-face approach be taken as well as flexibility from the researcher around time and place for interviewing. Initial introductions are vital for establishing good rapport and open communication lines. Showing appreciation for the time spent through the sharing of food or a small gift would take place at the end of the data collecting stage. The sharing of findings in an open and respectful way was also a critical component.

Another factor that was identified as a possible obstacle for ownership and participation was the participants' confidence in using English to express their thoughts and ideas. The fact that language might be a barrier for some participants was discussed and it was decided that due to the small-scale nature of this research, using an interpreter to support with language translation would not be feasible. Therefore one of the attributes for participant selection was their confidence to share their experiences and ideas in English. The research information sheet and consent 
form were both translated into Samoan to support the participants with understanding what was involved if they elected to participate.

I have been a teacher at the school selected on and off for the last ten years and currently hold a position within the senior management team. The relationships I have within the school community already can be seen as advantageous but may also hold some limitations. It is important not to undervalue the role established rapport plays in qualitative research. The relationships already established with the participants have been based on positive, honest interactions. I have had ongoing opportunities to gain their trust and respect. This I feel has supported my research not hindered it.

In order to get open and honest dialogue my role as a researcher rather than a teacher needed to be clearly defined. Being in a leadership position meant that I needed to convey to the participants that the research process would be on an equal footing to counter the power relations that were likely to be present. The primary aim was to convey to the parent and student participants that they had something of value to say, that their experiences and ideas would be heard and used in ways that make a positive contribution to our understandings of home reading practices. I aimed to promote the idea of power sharing and identified that the positive information provided could be used in purposeful ways to strengthen home-school partnerships.

It is identified that the 'interviewing relationship is fraught with issues of power who controls the interview, who controls the results, who benefits' (Merriam, 1998, p. 86). By acknowledging this, I endeavoured to be nonjudgmental and respectful during all interactions. Part of being an effective researcher is ensuring your own personal views remain anonymous throughout the research process; this principle applies regardless of the site being known or unknown.

An issue identified by Anae, Coxon, Mara, Wendt-Samu, and Finau (2001) is that recruiting Pasifika participants can be difficult for non-Pasifika researchers due to their lack of knowledge of Pasifika networks and structures. By having established relationships within the community I work, this issue could be addressed. The power and value of working within your own community to foster positive interactions 
between home and school sites, that could be beneficial for all involved is critical to this research.

For many Pasifika parents, teachers are held in high regard and there is an underlying trust that it is the teacher's role to educate their children and they may not always be confident or comfortable in a school setting (Fletcher et al, 2009; McNaughton, 2001). Therefore an overarching goal for me as the researcher was to convey that communication with parents is most effective when teachers listen with respect so 'stories and wisdom of families can be heard, acknowledged, responded to and valued' (Kay et al., 2010, p.417). This approach aligns with Pasifika methodology, the notion of Talanoa as a way to discuss and share ideas was employed. Talanoa is known in the Pacific region as a talking methodology. Its meaning can be broken down, 'tala' meaning 'talk' or 'story' and 'noa' meaning 'nothing' or 'void'. 'Noa' can also mean 'never ending' or continuous. (Amituanai-Toloa, McNaughton, Kuin Lai \& Airini, 2009, p.39).

Fletcher, Parkhill, Fa'afoi, and Morton (2006) identify that using Talanoa methodology both supports and challenges traditional approaches to qualitative research. It uses a less formal (unstructured) structure for interviewing participants, to allow for more free flowing conversations. This type of oral, interactive approach aims for more shared ownership over direction and discourse (Fletcher et al., 2006). By using Talanoa methodology, the aim is to facilitate a culturally sensitive, collaborative approach between the researcher and the participants as they tell their experiences. Talanoa research is all about 'storying', based on face-to-face verbal interactions between researchers and participants (Vaioleti, 2006).

To ensure trustworthiness of this research I aimed to ensure my own personal views of students, parents and my philosophy of teaching and learning did not bias the interpretation of data. When considering issues of validity, the following strategies were used. There was triangulation of interview data through analysis of both parent and students interview responses. Member checking took place during the follow up interviews, through the second Talanoa session with parent participants and transcript checking with the student participants, in order to clarify ideas and findings in a collaborative way. 
This process of member checking allowed me to check my interpretations of the participants' experiences and the ideas shared with the participants themselves. As the researcher, I shared key parts orally with the participants to support with meaning and comprehension of the transcripts. This collaborative and consultative approach to data sharing is consistent with the Pasifika Education Research Guidelines (Anae et al., 2001). It allowed for further dialogue, consultation and ownership between the researcher and participants.

\subsection{Research Design}

\subsubsection{The Setting}

This research was carried out at an urban contributing decile 2 primary school in a New Zealand city. The school caters for Years $1-6$ and at the time had approximately 190 students. It is a diverse, multicultural school with a wide number of ethnicities represented. During the time that the research was undertaken the Pasifika student population made up $35 \%$ of the school roll, with $25 \%$ identified as Samoan.

\subsubsection{The Participants}

Purposive sampling was used for participant selection. Current Samoan parents were identified from the school database who met the set criteria. The established criteria included the following attributes;

- Born in Samoa

- Some experience of schooling in Samoa

- Parent of a currently enrolled Year 4-6 student

- Confident to share their experiences and ideas in English

- Had been part of the school community for more than 1 year

These attributes were selected in order to gain insights into Samoan born parents with school experiences in Samoa and the impact this has when contributing to a new and different education system for their children in New Zealand. 
All potential parent participants were approached in person to gauge if they were interested in participating and to confirm that they met the set criteria. The number of participants who fitted the criteria was small. In total there were eight eligible families and from this five parents expressed an interest in participating after the initial consultation meeting was held. These parents were given the option of who would participate, either one parent or both. All five female parents elected to be interviewed individually. The five parent participants' children were also interviewed.

For the confidentiality of the participants' identities, their names are not mentioned in the research, rather they are referenced as Parent Tasi, Parent Lua, Parent Tolu, Parent Fa and Parent Lima. The Samoan numbers from one to five. The children's responses were grouped so numbering was not needed meaning no direct quotes were used.

\subsection{Data Collection}

One of the key principles guiding data collection for this research came from The Pasifika Education Research Guidelines (Anae et al., 2001). Empowerment comes from active and positive consultation with participants throughout the research process. Here the term empowerment is used both for the researcher and people being researched. The procedures followed during this research aimed to support this. Data collection comprised of four parts.

- Initial Parent consultation meeting

- Parent Talanoa Interview One sessions

- Parent Talanoa Interview Two sessions

- Student Pair Talanoa Interview sessions

\subsubsection{Initial consultation meeting}

An initial consultation meeting with parents was held in order to achieve more equal power sharing of the research process. This was intended to help address the balance of power and provide a greater level of consultation between myself and the 
participants. The initial process had been to have one meeting involving all eligible participants but due to time and coordination restrictions involving the participants, two meetings were held.

At both initial meetings the research topic and purpose were shared with the parents with feedback being sought. It was outlined that how the data would be collected was based on parent participant choice and that they could nominate how they would like to share their experiences and ideas. The purpose of this was to allow for consultation regarding data collecting therefore giving parents a greater level of input to ensure appropriate levels of comfort and safety were achieved. The type of interview that parents could nominate to participate in ranged from individual, to pair or group.

From the initial consultation meetings, five parent participants volunteered to participate and consent forms were shared and completed at this stage. Information and consent forms were available in both English and Samoan. Having the forms in Samoan was used to aid with understandings of the research and was deemed to be culturally appropriate and recommended by my Samoan advisor. It was evident by the response from individual participants that this was valued and appreciated. The general topics to be discussed during parent Talanoa interviews were given out and briefly explained. The purpose of this was to allow the parent participants time to think and reflect on their ideas and experiences before attending interviews. This was a further recommendation given as consideration for the participants whose first language was not English.

The Pasifika Education Research Guidelines (Anae et al, 2001) identify face-to-face interviews, either with individual or groups, as the most effective type of qualitative interviews for Pacific peoples. These interviews need to allow participants to build familiarity not only with the researcher but also with the research topic, questions and methodology.

All five participants elected to be interviewed individually rather than in pairs or as a group. The Talanoa interviews were audiotaped and transcribed. An interview protocol was established to ensure consistency and clarity during data collecting. Audiotaping is identified in the Pasifika Education Research Guidelines (Anae et al., 
2001) as a potentially problematic area for Pasifika participants. In order to address this, clear explanations about the value and purpose of audiotaping were shared with participants to avoid any anxiety or concerns about their experiences being taped. The existing rapport between the participants and researcher also helped with this.

By audiotaping the Talanoa interviews, I was ensuring accurate recording of everything that had been said and looking for any possible improvements to my own questioning techniques.

\subsubsection{Parent Talanoa Interview One}

Parent Talanoa interviews were held at times and locations that had been nominated by the five participants. During these interviews a 'Talanoa' (conversation) format was employed.

An informal trial interview took place prior to individual Talanoa interviews being held to trial questions and establish which ones might be confusing and need rewording as well as helping with question ordering. This was informal and no data from it was included in the research findings.

Each Talanoa interview began by asking the participants to share some details of their own family backgrounds (See Appendix A: Parent Background Information). The Talanoa interviews were based around pre-prepared questions, but flexibility was used, to allow parents the opportunity to guide and/or elaborate when they wanted to. A set of main questions with secondary probes were formed to help with elaborating ideas and seeking more in-depth answers (See Appendix B: Talanoa Schedule for Parents). The main questions discussed during the Talanoa interviews were grouped into four key areas;

- Their own school reading experiences

- Their perceptions, beliefs and values about reading

- Current home reading practices being employed

- Their knowledge of school reading practices 


\subsubsection{Parent Talanoa Interview Two}

A second individual interview was held with the five participants in order to share back orally the interview transcripts. This provided clarification and feedback for myself as the researcher as well as using the strategy of member checking for validity. This approach supports two key Pasifika values as identified in the Pasifika Education Guidelines (Anae et al., 2001), the importance of talking things over and using verbal negotiation when interacting with Pasifika parents. It meant the information was shared orally in a supportive way rather than giving the transcript written in English. This also aimed to allow the participants to decide what was important rather than the researcher seeing or ignoring meanings that do not fit with the research (Nakhid, 2002).

The second Talanoa interview sessions also allowed for further questioning and opportunities to clarify some perceptions and thoughts recorded during the first Talanoa interview sessions (See Appendix C: Talanoa Two Schedule for Parents). The need to do this came about after some initial analysis of the transcript data recorded from the first Talanoa sessions. It became clear that more information was needed on the skills being taught by parents, teachers and the church in Samoa in order to link this to the cultural values and knowledge of New Zealand reading practices.

In order to support the participants clarify some of their thoughts further on learning to read and what components are important when learning to read, their responses were combined together to form a summary list. The participants were asked to rank this list in terms of importance as well as add any additional ideas. A list of responses was also compiled in a similar way for the differences about learning to read in Samoa and New Zealand (See Appendix D: Parent Talanoa Summary Lists).

The Pasifika value of the significance of gifting with food or using another form of appreciation was important to acknowledge. Therefore a 'gift' for participating was given in what was deemed to be culturally appropriate. 


\subsubsection{Student Group}

The parent participants' children were also interviewed. If a parent had more than one child attending the school, their oldest child was selected. The age range was from 8 to 11 years old. The purpose of these interviews was to add student voice and help inform if there were common understandings between parents and their children regarding the connections between home and school reading practices. In addition these interviews aided with data triangulation. Questions were formulated that allowed for links to be made between parent and student interview responses. For the student participants the questions asked aimed to establish what reading experiences were like at home, who helps and how, and if school reading activities or practices are used. (See Appendix E: Talanoa Schedule for Students).

The aim was to interview the parent participants' eldest child but participation for these students was optional. As many of the school's Samoan families are large there was the opportunity to interview another family member if necessary. This opportunity did not need to be taken up, as all students approached were willing to be involved.

The students were interviewed in pairs. This allowed the students to support and prompt each other through the interview process. These interviews took place at school, a setting that was familiar to the students and allowed for easy access by the researcher.

During all the data collecting stages, my reflections were recorded in order to add descriptive notes of behaviour observed and to begin to think about the themes that started to emerge for data analysis. 


\subsection{Data Analysis}

After transcribing the interview data collected, the transcripts were read several times to obtain a general sense of the information gathered and make some early interpretations. This initial analysis showed a number of common experiences across the parent participants regarding learning to read in Samoa. It also showed that as a group, their knowledge of school reading practices in New Zealand were limited.

A coding process was developed to organise the data. This presented a set of specific words that continued to run throughout all of the participants' transcripts. This way of coding helped to locate the participants' perceptions and the meanings assigned by participants to specific words. These words were highlighted and then grouped to form the three key themes of oral language, rote learning and decoding.

The data also needed to be grouped into different sections for analysis and to aid answering the preposed research questions.

The sections devised from the research questions included;

- The parent participants' memories and experiences of learning to read in Samoa

- The home reading practices being employed by the parent participants

- The children's views of home reading practices

The three key themes of oral language, rote learning and decoding are evident throughout the different sections.

A separate section looked at the parent participants' knowledge of school reading practices in New Zealand. This was used in conjunction with the participants' experiences of learning to read in Samoa to analyse if connections or disconnections could be made between home and school reading practices.

\subsubsection{Rogoff's three planes of analysis}

Rogoff's (1995) three planes of analysis framework was used to further support with the coding and interpreting of data. Using Rogoff's three planes of analysis allowed 
for interrelating and interpreting of the emerging themes as they relate to connections or disconnections between home and school reading practices as well as identify the key social and cultural values and actions of the participants.

Rogoff's (1995) planes, as described in Chapter Two, are defined as participatory appropriation (at the personal level), guided participation (at the interpersonal level) and apprenticeship (at the community/institutional level). Emphasis is placed on the patterns of participation that occur in sociocultural activities. These planes do not sit in isolation from one another; making the individual and environment interdependent. The first plane shows the individual on their own, the second shows the social influence of others and the third shows the cultural influences. This framework provides the researcher with a lens for describing the adult and student participants' experiences of learning to read. It also provides insights into the impact literacy settings beyond school have in shaping one's literacy experiences and acquisition.

Triangulation of data was achieved by analysing the similarities and differences between the parent and students interviews. By interviewing parents and their children, insights into the perspectives of both were gained and explained through the three identified themes of oral language, decoding and rote learning and the interconnected planes of analysis (Rogoff, 1998). This cross checking of information was then used to strengthen the conclusions made.

Data analysis became a collaborative process, with input from the participants as well as support from my Samoan advisor and supervisor to capture the cultural and personal experiences of the participants was critical to ensure an honest, in-depth picture emerged.

\subsection{Ethical considerations}

This research was subject to the requirements of Victoria University of Wellington Research Human Ethics Policy with approval being gained before research began. There was a strong emphasis placed on aligning the research with culturally appropriate procedures recommended by the Pasifika Education Research Guidelines 
(Anae et al, 2001) and NZARE Ethics Guidelines. Practical advice was also gained from my supervisor and Samoan advisor.

The Principal of the primary school selected for this research was approached and consent was sought for this research. He was informed of the proposed research in a personal meeting with the researcher and in an information letter and made aware of what would be expected from the school, the teachers and the students involved. Permission was gained for the research on the understanding that the researcher would be responsible for the conduct of the research.

Interested parent participants were invited to attend initial consultation meetings where the research project was outlined. An Information Sheet for the research was shared at this time and potential participants understandings of the study was gauged. It was made clear that their participation was voluntary. Consent forms were gained from the participating parents.

A meeting was held with the student participants and the purpose of the research project was explained to them. The researcher had already gained consent for them to participate in research project during the parent participants meetings. All five students agreed to participate in the research and permission slips and information letters were shared and signed.

If at any time, a student requested that something not be shared with others, it was not recorded and would not appear in the final report. Their ideas remained confidential to the researcher and student participant. This safe guard was applied to the parent participants as well. The strategy of member checking also helped to ensure participants' safety. If negative experiences by either student or parent participants, were expressed an ethical decision regarding if they are recorded or not was made by the researcher.

Confidentiality for participants is critical. For Pacific peoples the issue of confidentiality can be centred on the "concern that their personal and/or family information might be inappropriately exposed and thus bring familial and personal shame" (Anae et al; 2001, p. 40). To safeguard against this it was important to ensure 
that all participants have a clear understanding of the protocols in place regarding confidentiality, parent participant input into how these protocols looked was sought and discussed at the initial parent meeting(s).

A point to make is that "protection of confidentiality occurs more by the establishment of confidence and trust between the interviewer and interviewee, than by the mere signing of written ethics consent forms" (Anae et al; 2001, p. 40). The parent relationships that have already been established with myself can be seen as advantageous in this regard.

The following appendices have been included;

Appendix F: Information Sheet for School Principal

Appendix G: Consent Form for School Prinicpal

Appendix H: Information Sheet for Parents (English/Samoan versions)

Appendix I: Consent Form for Parents (English/Samoan versions)

Appendix J: Information Sheet for Students

Appendix K: Consent Form for Students

\subsection{Limitations}

This is a small-scale piece of educational research, that involved a small sample of participants and therefore any findings or conclusions drawn here are not generalisable. In addition to this, unfortunately one of participant was unable to complete a second Talanoa session due to her family moving to Australia. This also meant that one child was unable to be interviewed.

The parent responses are taken at face value. No attempt was made by myself to verify what the parents reported, their responses are based simply on childhood reading memories and experiences and what reading practices they identified they participated in with their children.

Like any researcher, I have attempted to remain neutral through this research but the way the parents' responses have been interpreted, is likely to have been influenced by 
my own cultural background and professional training. That is the nature of social science based research and a common limitation for beginning researchers. As the primary researcher and holding a senior management position at the selected school, being seen in a position of power by the student and parent participants may have also had an impact.

The parent participants' understanding of the questions being asked could also be seen as a limitation. There were times when some of the participants experienced language difficulties when trying to articulate their responses to certain questions. My limited knowledge of Samoan customs and values and the language may have also hindered our Talanoa sessions at times. 


\section{CHAPTER FOUR: FINDINGS AND DISCUSSION - A SAMOAN CONTEXT}

\subsection{Introduction}

Chapters Four and Five combine the research findings and discussion to explore the participants' thoughts and cultural values on learning to read. The aim is to enhance understandings of the role social and cultural practices have on reading acquisition for this group of Samoan parents and their children. Central to this research is an understanding that reading practices vary for different cultural groups, leading to different interpretations and values of how we learn to read and the impact this may have on home and school reading practices.

From exploring the primary research question which sought information on how do the cultural values and experiences of Samoan parents influence the home reading practices they employ with their children, it became evident that the five parent participants were expressing similar cultural interpretations of how children learn to read. These interpretations were then used to identify if there were any shared understandings of reading practices between home and school for these parents. From this the researcher was then able to look for evidence of connections or disconnections between home and school reading practices.

Chapter Four explores the participants' cultural values and experiences of learning to read in Samoa through the literacy sites of the Pastor's house, primary school and home. The participants' memories and experiences are grouped into three themes that represent the key literacy practices that have contributed to their understandings of reading acquisition in Samoa. The identified themes are the importance of oral language, the role of rote learning through repetition and memorization and lastly decoding accurately.

Chapter Five contains the findings and discussion on home reading practices being employed by the participants in New Zealand and their children's views of home reading practices. The participants' knowledge of New Zealand school reading practices is also explored. From these findings, the connections or disconnections 
between school and home reading practices for the participants and their children are identified.

Each chapter contains a series of participant responses that help to build a rich picture of the cultural and social practices that have helped shape and influence the values and actions around reading acquisition for these participants both in Samoa and New Zealand.

As outlined in Chapter Three, a socio-cultural perspective has been taken to interpret findings and frame the discussion. The fundamental belief here is that literacy is tied to a person's cultural and social background - the languages, values and beliefs that these bring to make meaning and gain identity (Pahl \& Roswell, 2005; Street, 1997). This perspective sees literacy as a social process - a cultural activity (Nieto, 2010). It is also important to note that as for any cultural group, literacy in Samoa is based on the cultural values and beliefs held by its people. Samoan literacy is associated with cultural behaviour, traditions and family and church expectations (Tuafuti, 2000).

Rogoff's three planes of analysis framework (1995) sits within a socio-cultural perspective and is used to interpret the findings. It is a framework that allows emphasis to be placed on the patterns of participation that occur in socio-cultural activities, through the three planes of participatory appropriation, guided participation and apprenticeship as the participants learn to read. The aim is to use a sociocultural analysis approach "that requires considering how individuals, groups and communities transform as they together constitute and are constituted by sociocultural activity" (Rogoff, 2003, p. 161). Using this framework will enable the cultural values and experiences of the participants to be unpacked which will provide insights into rationale for the reading practices they undertaken and use in New Zealand.

Rogoff's framework (1995) is multidimensional which allows human relationships and interactions to be viewed in different sites in relation to reading acquisition and practices. Insights into the impact of literacy sites beyond school in shaping reading experiences and acquisition can be identified. It is important to understand that all 
three planes; the individual, interpersonal and community within learning are not independent units but connected.

The adult and child participants' responses from the Talanoa interview transcripts are presented in italics to provide evidence of the emerging themes. Occasionally the responses have been lightly edited for clarity. This editing has only been used when necessary to ensure responses are grammatically correct and care has been taken to ensure that the meaning has not been altered in any way. A set of guiding questions were used (See Appendix B: Talanoa Schedule for Parents), with additional prompts when needed. The responses stem from across the Talanoa questions.

\subsection{Three literacy sites in Samoa: Pastor's House, Primary School, Home}

The five parent participants' childhood memories and experiences of learning to read in Samoa came from three different literacy sites; the Pastor's house, primary school and home. For all the participants there were some common features within these sites. These features have been outlined briefly below to provide background information.

For all participants the role of the local village Pastor was hugely important in their shared memories and experiences of learning to read. The literacy sessions held at the Pastor's house were viewed as a critical component for reading acquisition for these participants. This finding is consistent with other research on Samoan literacy practices. Duranti and Ochs (1993) and Tuafuti (2000) have noted that within Samoan society the Pastor's role in teaching and learning is seen as a key component for early literacy acquisition. It is interesting to note that for all participants the experiences shared regarding learning in the Pastor's house were positive and memorable. It appears that the approach being used by the Pastor (and his wife) was supportive and community based for these participants.

All five participants interviewed had attended primary school within their village. In Samoa, children start school at age 5 and move on to secondary school at age 12 . The majority of children enter primary school with a good grasp of the Samoan language, 
through alphabet and Bible lessons with the Pastor and at Sunday School, with English lessons being taught daily at most schools (Pouono, 2009). For these participants, school generally finished at $1 \mathrm{pm}$ each day, with the rest of the day taken up with lessons from the Pastor, home chores and evening rituals.

In Samoa the traditional family home is the fale. A traditional fale is open, with no windows or doors and is a meeting place for family and guests, and an important place for extended family. The traditional fale is still the dominant form of housing in Samoa today but there are some families living in more European style houses. The Bible is the primary reading resource available and is an important part of daily life for many families (Dickie, 2008; Tagoilelagi, 1995). The Bible was seen by all participants as an important resource and regularly used within their own home environments.

While the three literacy sites are separate there are similarities across them in regards to reading practices. The sites all provided reading activities and experiences that have helped shape the participants' own cultural values and understandings of reading acquisition and learning. These shared memories from the different literacy sites are used to identify the cultural values and experiences. The impact of this on the home reading practices being employed by these participants in a New Zealand context in explored in Chapter Five. The participants' responses give insights into the relationships and interactions between the participants and their Pastors, family members and teachers as well as the wider community.

\subsection{Three Reading Themes: Oral language, Rote learning, Decoding}

From the five parent participants' childhood memories of learning to read in Samoa, across the three literacy sites, a series of key words emerged and these were then used to form three themes around learning to read and reading practices. The reading acquisition themes formed from analysis of the Talanoa transcripts were;

- The importance of oral language practices

- The role rote learning plays through repetition and memorisation 
- The strong emphasis on accurate decoding

The first theme of oral language involves the practices of listening, reciting and singing. As outlined in Chapter Two, Samoa has a strong oral tradition with listening and speaking skills being highly valued both culturally and academically. Historically, oral communication was the dominant practice used and is still evident today (Duranti \& Ochs, 1993; Tuafuti, 2000).

Rote learning through memorization, repetition and practice forms the second theme. Rote learning is based on the notion that the learner will be able to quickly recall the meaning of the material the more it is repeated. Often this can take place without an understanding of the reasoning or relationships involved in the material that is learned.

The importance of sounding out and pronouncing words correctly is grouped under decoding and forms the third theme. Decoding involves sounding out letter sounds and blending letters through phonemic awareness extending into pronouncing common spelling patterns correctly and building sight word knowledge (Ministry of Education, 2010).

From the findings of this research it could be suggested that the cultural values and beliefs connected with oral language, rote learning and decoding form the basis of Samoan literacy practices for these participants. These are culturally valued teaching strategies and practices when learning to read in Samoa. This reinforces the notion of literacy activities becoming cultural based community activities that through apprenticeship are passed down to the next generation (Rogoff, 2003). Analysis of the participants' responses and how they interpreted my questions showed a strong preference towards these three reading acquisition themes, which can be defined as skill based in orientation. This led to the interpretation that the participants' experiences of learning to read were based heavily around a code-based approach to literacy acquisition as described in Chapter Two; where the skills of decoding, memorization, recitation and rote learning are emphasised (Tunmer, Chapman and 
Prochnow, 2004). There is a greater emphasis in the early years of learning to read on teaching sounds and letters and word-level strategies.

It is crucial to consider the cultural and social impact this has on home-school connections for Samoan families engaged in the New Zealand education system. This will be discussed further in Chapter Six.

\subsubsection{Oral language - listening, reciting and singing}

The oral language skills of listening and speaking were highly valued by all participants. The participants' responses revealed some of the cultural influences that facilitated these oral language activities. It was evident that the participants felt that learning to read was strongly associated with listening. Listening carefully to the teacher was seen as important for making sure you were learning as well as being respectful towards your elders. The response quotes below provide examples of this, the importance of listening carefully to the teacher to ensure you could complete what was asked of you as well as not getting yourself into trouble. Here the teacher models a pattern of behaviour to the children. It is an example of how the participants are being apprenticed into their community's ways of reading (Rogoff, 1995).

The teacher has to read to you and you have to listen, you have to repeat and listen. (Parent Tolu)

And we used to listen to the teacher very carefully, if you are not doing your homework, you can get in trouble from the teacher. (Parent Fa)

Four of the five participants shared their experiences of learning English through listening to radio stories provided by the Samoan Education Department at primary school. Listening to the radio happened regularly and was a well-used tool for learning English (REF). The process involved a story being read in English with a series of questions asked at the end. The teachers would write down the questions read out on radio for the children to answer back in their own classrooms. 
Classes would come together and listen to the radio. To answer the questions live on radio, students are listening and preparing for the questions. We listen to the story, so you can answer and write down the answers in your own sentences. (Parent Fa)

Three classes would come together - you would all sit there and listen. A time was arranged to air it, so all schools could listen. They would read a story and ask questions about it. We would go back to our own class, to answer the questions. Then the next week, back for the same thing. We would relook at last week's work. There would be an overview of what was talked about last week.

(Parent Lima)

Another participant talked further about how the radio was used for singing and learning English. Singing was seen as an enjoyable and important way for this participant to memorize and practice words and phrases in both English and Samoan.

There was a programme on the radio, for all school - we would get together and sing along to the radio. After that the teacher would put all the songs together into charts. So that we could see the words and repeat them. (Parent Fa)

The teacher would write out the song and we would learn line by line. Traditional ones like Mary had a little lamb and Humpty Dumpty. (Parent Fa)

Singing was a popular teaching technique used to support children with developing their oral language and reading skills. It was a technique used in all sites and a culturally based activity that was valued.

At the Pastor's house oral language skills were also practised through reading aloud and singing Bible verses. The participants explained how, as children they learnt to recite verses from an early age. The pastor and a group of children would start with Bible reading, with each child reading one verse at a time, with assistance if necessary. Here the interpersonal plane of guided participation by the Pastor and participants is in the foreground (Rogoff, 1995), through the shared reading of Bible verses while the community plane is also operating as the Bible is being used to transfer cultural and religious values and beliefs. A strong focus on oral language 
through reciting and imitating was evident in the participants' responses when discussing what happened at the Pastor's house.

It became apparent that the ways of learning at the Pastor's house were similar for all participants, activities that are shaped by cultural and social values. These are values that help shape one's own beliefs and actions. All the participants had strong memories of learning to read with the Pastor, as the responses below indicate. The responses show the Pastor's social and cultural influence in how the children participated and were supported in this learning environment. The literacy instruction at the Pastor's house also shows the cooperative nature of tasks (Duranti and Ochs, 1993) and provides further examples of young children learning through guided participation (Rogoff, 1995).

We would sit in a circle, and then we read one sentence each so it goes around like that. The teacher or Pastor listens then if someone says the word differently he corrects it. (Parent Tasi)

Reading the Bible out loud - that was the reading lesson when you went to Sunday school (with the Pastor). Reading verses - we tried to read and repeat them. (Parent $\mathrm{Fa})$

We would have turns to stand up and read the alphabet. One by one. The Pastor would say it again and we would have to repeat it. (Parent Tolu)

In these examples above the Pastor guides and supports the learning of the alphabet and Bible verses by providing a scaffolded learning structure and modelling when necessary. Within this teaching practice by the Pastor, the interpersonal plane (Rogoff, 1995) is evident as the younger children are exposed to the more advanced tasks being completed by older children (Duranti \& Ochs, 1993), allowing the younger children to be immersed in learning in a supportive and collective way.

Participation would be based on competence, when a task was mastered, a more complex one would be taught. As noted by Duranti \& Ochs (1993), "tasks are seen as cooperatively rather than individually accomplished" (p. 214). Here a direct connection can be made to guided participation (Rogoff, 1995), the children are able 
to observe and then participate in the learning activity when it is considered appropriate.

One participant shared her memory of attending the Pastor's house regularly from a very young age, so that by the time she was expected to know the Samoan alphabet she could recite it quickly and accurately, as she had heard it so many times before that it had become embedded. Guided participation can be defined as observation as well as the hands-on involvement in a set cultural activity (Rogoff, 1995).

As in the school site, singing and the rhythm of speech were used to aid children when learning to read. The Pastor would focus on pronunciation and reciting aloud, often playing a supportive role through repeating or rephrasing to ensure the children recited the word(s) correctly. This is another example of guided participation (Rogoff, 1995), when the children are participating in culturally organised activities that reinforce the importance of speaking skills. Singing in this context can be seen as developing oral skills of reading aloud as well as an activity that is culturally valued as illustrated by Parent $F a$,

The pastor would say when reading the Bible, it's more like you are singing a song, so when there is a punctuation mark - I had to stop and read correctly. (Parent Fa)

The participants' responses revealed that proficiency in oral language was important. Being a good orator is highly valued in Samoa (Tuafuti, 2000). The importance of being able to articulate and pronounce words and/or verses aloud clearly as described by the participants and valued by their communities, is seen as strength by Samoan people (Duranti \& Ochs, 1993; Tagoilelagi, 1995; Tuafuti, 2000). Developing oral skills was not just confined to the Pastor's house or church. Within the home site, singing was also used and valued as a learning tool;

Singing was really important - mum and dad would sing at night, in bed, all singing together. Singing and laughing. Singing is the other thing, to help it makes sense.

(Parent Tolu) 
Reading the Bible, I loved reading the Bible and singing church songs, my parents were good at this. (Parent Lua)

As within the school site, the Pastor also used the radio as a literacy tool. Samoan radio stories would be played to the children with the Pastor stopping the story at times to ask questions. This could be interpreted as a way to develop children's listening skills as well as aid meaning and understanding of text.

All the kids would sit down and listen to the story, what it is about. Then the Pastor would stop the radio story and ask questions, what it was about. (Parent Tolu)

The important role oral language played in the home was described by some of the participants. As young children, they were expected to be able to communicate messages orally to adults. This has been noted by Duranti and Ochs (1993) who state that young Samoan children are asked to communicate messages orally to others by their parents and other community members (p. 221). It is clear that the ability at a young age to speak accurately is culturally valued and an expectation placed on Samoan children.

Listening carefully was essential to ensure accurate hearing and interpreting in order to follow instructions and communicate with others. This was expressed further by one of the participants 'families are learning from mouth to mouth, getting words like that'. (Parent Lima)

(Traditionally) In Samoa, we don't have telephones, mobiles - texting. So its very important when you parents tell you to go to the shops that you listen, you don't have a list, so you have to memorize. (Parent Fa) 


\subsubsection{Rote learning-memorization, repetition and practice}

The importance of rote learning was strongly evident, as all participants talked about the role memorizing, practising and repetition played when learning to read. The bottom up approach emphasises these skills with making meaning playing a secondary role (Tunmer, Chapman and Prochnow, 2004). When sharing their memories of learning to read at primary school, practising was identified as a common activity that happened regularly. This was done through reading activities that included practising the alphabet aloud, recalling words on their own and simple sentences through repeating them orally or copying down. Examples of these tasks are presented below.

We would practice our letters. Written from the teacher, how to write my name and then practice it heaps of times. We would write down the words too. Writing it down about 10 times. Lots of practice. (Parent Fa)

We started with small words, look at the word on the board, spell it out and then put into sentences. We would copy and practice them. (Parent Lua)

This way of practising was not just limited to school, often this type of activity would be used for homework too. As sets of home reading books were not available, the teacher would often instruct that a set of simple words and/or sentences be written down and taken home to practice.

We would write into our books, then the teacher would correct them, if the words were not correct, the spelling of words - then write 5 or more time - practice, practice! (Parent Tolu)

The participants identified repetition and memorisation as learning strategies used at school. These strategies were used often by teachers to guide and support children when learning to read. This is again an example of Rogoff's guided participation plane (1995) being in the foreground, where children are participating in a cultural organized activity that is valued. The cultural belief was that the more you repeated and practised the better reader you became. The community plane (Rogoff, 1995) is 
also in evidence here as cultural practices are happening within the institutional context, of primary school.

Much of this teaching was whole class with the teacher modelling or telling the child or children when errors were made. The teacher would provide the correct model and the children would practice again. This teaching approach could be due to environmental factors for example lack of literacy resources available, large class sizes but also seen as culturally appropriate and common practice in Samoan primary schools.

At school, for reading would we would sit on the floor. A story or paragraph would already be written out on newsprint or blackboard by the teacher. The teacher would read first. Then she would choose someone to read, to read in front of everyone. You had to stand up and read. Then she would point out if anything was wrong and she would correct it after. It was our routine, the whole class would do it like this.

Parent Lima

The participants identified that the teacher would often provide a model for them to copy and repeat. This model was often given orally by the teacher, which the child would respond to or imitate (Tagoilelagi, 1995). This way of scaffolding learning, through guided participation (Rogoff, 1995) demonstrates the importance of pronouncing words correctly but also being able to communicate well orally.

A child would.. Repeat themselves and have another go or the teacher stops the kids, and lets the kids catch up, all practising together. (Parent Tasi)

Teachers would always repeat the words if you got stuck. (Parent Lima)

There would be an activity on the board - a word on the board and then into a sentence. We would memorize it. (Parent Tolu)

As well as in the school site, examples of rote learning were also strong in the participants' shared memories of their reading experiences at the Pastor's house. At the Pastor's house, the participants as children, participated in literacy activities that 
involved them learning and practising the Samoan alphabet, writing sentences and Bible verses illustrating Duranti and Ochs (1993) explanation that church literacy is based on rote learning and oral presentation of biblical texts, which are read and memorized.

Another teaching practice example that strongly emphasised memorisation, repetition and practice was learning the alphabet. All of the participants experienced learning the Samoan alphabet through the Pi Tautau chart (Dickie, 2011; Tagoilelagi, 1995). They described how the teacher (Pastor or pastor's wife), would be at the front with the Pi Tautau chart and all the children would recite it together, first the letters with matching pictures then the letters alone and numbers 1 to 10 .

At that Pastor's house we were taught as a group and we learnt the Samoan alphabet. We learnt our reading as well. We sat in a group, alphabet in order. Sounding out the letters. (Parent Tasi)

When we got to the Pastor's house a big board with the Samoan alphabet on it, was already set up. You have to sit down and learn the individual letters. After the letter, you learnt a word, after the word you learnt a sentence.

(Parent Lima)

You had to practise writing the Samoan alphabet. Then after about half an hour, the pastor's wife would check your books.

(To see) Who's doing it right, if wrong she would correct it. She would correct and the kids would practice again. (Parent Lima)

When Parent Lima expanded further on the help received from the Pastor's wife if as children you got some of the alphabet wrong, it was clear that the correct model was modelled to the children on an individual basis, although the other participants did not mention this practice of individual tuition. The fact that Parent Lima came from a small remote village in Savai'i may account for this variation in practice. Here the personal plane (Rogoff, 1995) is foregrounded, as the children worked on a set reading activity independently before any adult support was provided. Guided 
participation then occurred when the Pastor's wife worked on an individual basis with the children to check their alphabet work.

After lessons on the Samoan alphabet were completed there would be Bible reading, each child would read one verse from the Bible, with adult assistance if necessary. As described by Duranti and Ochs (1993) children would learn to recite verses from an early age. The Bible was critical for practising reading aloud and memorization.

The Pastor would put the kids into a circle, reading from verse to verse - repeating like that, so the kids would all have a turn. (Parent Tolu)

We read from the Bible, about one verse - we tried to read and repeat it. The Pastor would say it and we repeat it. (Parent Tolu)

These interactions reveal the interconnected nature of Rogoff's planes of analysis (1995), as the participants learnt to read the Bible. Much of the interaction here is interpersonal where the participants described how guided participation (Rogoff, 1995) between themselves and the Pastor or the Pastor's wife occurred. The personal plane (Rogoff, 1995) is evident when the children practice saying a set verse on their own. But it is also relevant to consider the community plane, as Bible reading is seen as a valued cultural practice so that the connection between family and the broader social-cultural context, of the church and religious beliefs, is maintained (Rogoff, 1995).

These teaching practices of literacy reflect what the community, in a social and cultural context, culturally valued. Here the Pastor and church functions to promote Fa'asamoa $^{2}$ to support Samoan cultural beliefs and values, in conjunction with literacy learning. This type of literacy is "about oral language, memorisation, and transmission of beliefs and values that enlighten the knowledge of heritage and ethics" (Tuafuti, 2000, p.10).

\footnotetext{
2 The Samoan way of life, the way of our ancestors
} 
As identified earlier the Bible was not just seen as a reading resource but also as an important part of cultural practice in developing reading acquisition for Samoan people. Bible reading was not restricted to church or the Pastor's house. The experience of reading the Bible at home together was a common occurrence for all the participants. It would involve reading a Bible verse aloud with other family members. This shared reading experience allowed the participants to practice reading aloud as well as be support by others if words were too difficult to pronounce. This example shows how "guided participation (Rogoff, 1995) is influenced by patterns and disposition towards culturally structured activities that exist in families and are passed down between generations" (Love \& Hamston, 2003).

These interactions provide another example of the interconnected nature of Rogoff's planes of analysis (1995). The personal plane as individual practice takes place; Practising - everyday after school, I would go home and read the Bible. (Parent Fa)

The interpersonal plane when Bible reading becomes a culturally organised activity between family members.

After lunch, my mum would always practice reading the Bible with me. She would read to me and I would listen and try to read - repeat after her. This was our main book to learn from. (Parent Tolu)

We would have turns with reading the Bible - verse by verse. The leader, one of my grandparents, would read first, then the rest of the family would response - read a verse too. (Parent Lima)

The community plane (Rogoff, 1995) within the home setting, through shared reading of the Bible, shows how memorisation and repetition were valued cultural aspects of learning to read. The reading of the Bible is a strong and popular reading activity for Samoan families (Tuafuti, 2000). This strong tradition has been passed down through families and communities. An illustration of how cultural tools are inherited and transformed by successive generations (Rogoff, 2003, p.51). This also creates a strong link to church related teaching and learning practices across the sites of home and church, the cultural influences on activities through apprenticeship (Rogoff, 1995). 
This emphasis on reading aloud and memorization, were reading practices that were culturally valued by the community (Duranti \& Ochs, 1993 and Tagoilelagi, 1995) and the participants within this research, as children were apprenticed through the three literacy sites of the Pastor's house, primary school and home.

\subsubsection{Decoding - Sounding out, correct pronunciation}

All participants stressed the importance of being able to sound out words correctly and talked about their experiences of feeling confidence with this in their first language but not always being able to pronounce words in English accurately. Their primary school teachers would use the teaching strategies of modelling and telling to support them with word pronunciation. Children would be expected to listen carefully and practice to ensure the correct pronunciation was mastered. This suggests that being able to pronounce words accurately was seen as a strong indication of success when learning to read.

Below are some of the participants' responses to how this teaching strategy was actioned in the classroom. These responses again indicate that a shared reading approach was being used. Initially all the children would be reciting the alphabet or words together, then the teacher might select individual children to recite on their own, as the last response shows. This pattern of social interaction, demonstrates how Rogoff's planes of analysis (1995) can overlap each other. Both the personal and interpersonal planes are evident here, through the children being engaged in guided participation with others as well as working on an individual level.

We sat in a group, and said the alphabet in order. Sounding out all the letters. (Parent Tolu)

Sounding out words, sometimes the shape - cutting out shapes of words to fit the matching words, finding the words they matched to. (Parent Lua) 
The teacher would write down a poem and we would read the correct pronunciation of the words. (Parent Lima)

Sometimes she would ask us to say it, how many syllables. And make sure pronunciation was right. (Parent Tolu)

Sometimes the teacher writes and all the class reads then we pass the book on, from the first child then we read a sentence and pass it on. The teacher can correct it, the teacher would tell you the right pronunciation. (Parent Tasi)

There is a solid connection between pronouncing words correctly, repetition and listening for these participants that is clearly evident in the responses below. This again illustrates how the teaching strategies being employed can be interpreted as having a strong cultural emphasis and value for these participants. It shows how as children, these participants are apprenticed into the values and practices of school literacy in Samoa.

The teacher would say here's a story about.., the teacher who choose a kid to stand up and read, if they got stuck on a word, couldn't pronounce it properly, the teacher would say, say the word 3 times, repeat it, then go back to the start and read again. If you say it properly, go back to the beginning and read it again. (Parent Fa)

Listen to the teacher, listen to her pronunciation, I would point to the letter the teacher would say. (Parent Lima)

\subsection{Access to Literacy Resources}

A final area to consider when thinking about reading acquisition and practices in Samoa is access to resources. All participants identified the lack of reading resources that were available while attending primary school in Samoa. It is important to consider the impact of this on literacy learning and teaching. But is also essential to put this lack of resources into context historically, as access to and quality of 
resources may be different in the present climate from when these participants were learning to read in Samoa.

For the participants, at school it was common practice for the teacher to have the only copy of a book so the teaching of reading involved shared reading or being read to. The chalkboard and big sheets of paper were often used to record learning onto. The teacher, to be used for reading practice, wrote out passages of text, short sentences, poems and songs. This would have a noticeable impact on the reading practices and techniques that could be implicated by teachers. There would be practical restrictions for both teachers and children.

This was a belief held by Parent Lima, she felt that how reading was taught in Samoa, through all reading together and the teacher correcting you in front of the class was because of the lack of books and reading resources available. It had to be shared reading experience.

Not many books, you can't read yourself - the teacher has to read to you and you have to listen. The teacher has it, you have to repeat and listen. The teacher has her own book, like a long word - she will write it on the board, to spell and write it and learn it. You have to write the word many times. (Parent Lima)

Sometimes the teacher would write down a sentence and you would have to take it home and write it down 10 times, that was our homework. (Parent Tolu)

Only the teacher had a book because there are not many resources on the island. The teacher would write on the board. Everything on the board, lots of writing on the board at the end of the day. We didn't have books by ourselves. Everything on the board. (Parent Tolu)

All the class reads then we pass the book on, from the first child then we read a sentence and pass it on. (Parent Tasi)

This clearly had an effect on home reading activities too. For four out of five participants the only 'book' they had access to was the Bible when at primary school. 
If the children did take homework home it was likely to be an exercise book with some words or sentences written out by themselves or the teacher to practice, no a set school reader. Unlike what happens in most New Zealand schools, were home readers are sent home on a daily basis.

At home just the Bible and some Samoan books - we would try and read to ourselves. Not many books. (Parent Tolu)

The bible mostly, no other books, only had a chance to take books home from friends when I was in college, we swapped (our novels, romance ones) and also a chance to go to the library in Apia. (Parent Tasi)

Some of the participants talked about using the resources from their local environment, with one parent participant sharing her experience of how her teachers would ask the children in her class to bring natural resources in.

So when we did science, we would go out and look at things - like what is living, what is not. So when they count they would collect things, like sticks, tops of drink cans. (Parent Lua)

\subsection{Final Thoughts}

The findings in this Chapter align closely with earlier research on literacy practices in Samoa as outlined in Chapter Two. The strong cultural and social values around oral language, rote learning and decoding that are associated with Samoan literacy are highlighted throughout the participants' responses used (Duranti \& Ochs, 1993; Tagoilelagi, 1995; Tuafuti, 2000). These values are evident in the teaching and learning strategies for reading outlined in each of the three sites identified.

Links have been made to show how a socio-cultural perspective can be applied to these findings through Rogoff's three planes of analysis (1995) and socio-cultural theory (Luke \& Freebody, 1997; Nieto, 2010; Street, 1997). Socio-cultural practice, at a basic level means that all language happens in cultural and social contexts and is understood by individuals in terms of their own social and cultural backgrounds 
(Rassool, 1999). If literacy is linked to experiences, social and cultural identities become important factors for acquisition (Street, 1997; Luke \& Freebody, 1997; Nieto, 2010).

By investigating how learning to read is interpreted for this group of participants, understandings about how the reading practices the participants' children participate in and observe in their own home settings can be made. As stated by McNaughton, Amitanai-Toloa \& Wolfgramm-Foliaki (2009), parents' ideas come from a "cultural history of ideas about childhood, parenting and development” (p. 322).

This forms the basis for the following chapter, Chapter Five. The findings on home reading practices will be used to show how the participants' cultural and social experiences of learning to read in Samoa have strongly impacted on the reading strategies they employ when supporting their own children in New Zealand.

It is important to keep at the forefront of any discussion that literacy knowledge and practices are tied to individuals' cultural and social backgrounds - "the languages, values and beliefs that individuals bring to make meaning and gain identity for themselves" (Pahl \& Roswell, 2005, p. 5). 


\section{CHAPTER FIVE: FINDINGS AND DISCUSSION A NEW ZEALAND CONTEXT}

\subsection{Introduction}

This chapter provides further evidence and discussion to answer the primary research question of how the social and cultural values and experiences of these Samoan born parent participants influence the home reading practices they employ with their own children in New Zealand. This is done through exploring the home reading practices being implemented in New Zealand and investigating the knowledge of school reading practices for these parents.

The chapter is divided into three sections;

- The parent participants' home reading practices with their children

- The participants' children's responses to home reading practices

- The parent participants' knowledge of school reading practices

There is evidence that many of the social and cultural values and experiences of learning to read in Samoa have been transferred into home reading practices in New Zealand for these participants. It is clear that the previously identified literacy patterns and practices within oral language, rote learning and decoding are being valued and used to support their children with learning to read. In other words the reading practices that they were apprenticed (Rogoff, 1995) into when learning to read in Samoa are now being used with their own children. It is important to consider the social and cultural uses and meanings of literacy practices that these participants and their children are identifying with. As "family literacy practices reflect and build on social and cultural identities. Their ways of being in the world" (McNaughton, 1995, p.195). So within families and across communities, reading practices are being passed down. As discussed in Chapter Two, family practices reflect and build on people's social and cultural identities in relation to literacy (McNaughton, 1995; Pahl \& Roswell, 2005). It is therefore important to consider the role cultural identity plays when looking at the effect home reading practices have on home-school connections or disconnections. 


\subsection{Section One: Parent reading practices with their children in New Zealand}

The first part of this section consists of separate descriptions from each parent participant to highlight their key social and cultural beliefs and actions in relation to home reading practices. The separate descriptions also allow for a greater level of individual voice to be present. Following this, connections will be drawn to show where there are similarities in beliefs and actions between the participants. This illustrates the social and cultural values that help shape the reading practices being employed in New Zealand by these participants.

The participants' responses regarding their home reading practices align with recent research that Samoan families observed in New Zealand had maintained their social and cultural beliefs for literacy acquisition (McNaughton, Amitanai-Toloa \& Wolfgramm-Foliaki, 2009; Tagoilelagi 1995). It is evident from the participants' responses that emphasis is placed on word pronunciation through telling or modelling, along with practice and recitation. Literacy based skills that in Chapter Four have been identified as the key reading practices that these participants' participated in when learning to read as children in Samoa.

The role of the church in reading acquisition, through Sunday school lessons and home Bible reading, were evident in the participants' transcripts and has been incorporated into this chapter.

\subsection{The Five Parent Participants' Descriptions}

\subsubsection{Parent Tasi}

Parent Tasi identified that parents are perceived as first teachers and saw this as something that was emphasised strongly in New Zealand. An example was given of how in New Zealand parents are encouraged to read with and to their children. Parent Tasi felt that this contrasted with home reading practices in Samoa.

"When I came here I heard a lot of encouragement for parents to read bed time stories or even out of bed, any time to read but in Samoa no. I have never come across a parent who reads (school books) to their kids" 
A possible explanation for this could be that no home readers were sent home due to a lack of reading resources when these participants were learning to read in Samoa. It has also been identified that the Bible was often the sole reading book in many Samoan households.

Parent Tasi expressed her love of reading and that her children knowing how to read confidently was important. It was evidence that while her own home might not be well resourced with reading material, she wanted her children to be able to access and enjoy reading activities. She shared how as a family they would often go to the local library after school to ensure her children had access to books and that she could pass on her enjoyment for reading. Here guided participation can be seen as the interpersonal process of parents and their children being involved in shared reading practices at home (Love \& Hamston, 2003).

When sharing the reading strategies used at home, Parent Tasi noted that her children required different levels of support. Her older children were reading more independently and at times might need support with vocabulary and word meanings but often sourced the dictionary themselves when stuck on an unknown word. There was some evidence of her guiding them in this. For example when talking about her daughter, Parent Tasi noted that "she just went past the word-and got frustrated and asked me, so when I looked it up I found it. It was there in the dictionary"

With her youngest school aged child, Parent Tasi would let him read the story aloud first and support by making some corrections when words were not pronounced correctly. She would also use the pictures as a reference to check for word knowledge. This strategy of using the pictures to help a child make meaning is a common New Zealand junior primary school technique (Ministry of Education, 2010) and is an example of where home and school practices are in alignment. At the end of reading, simple questions about the story would be asked but she felt often he was unable to answer these.

Parent Tasi's family were not actively using the Bible as a reading resource. They had no Bible in English at home and her children's understanding of or interest in Samoan language, Parent Tasi felt was not strong enough for them to learn to read the 
Samoan Bible. She expressed mixed feelings about how her children had lost the Samoan they knew, once they started school in New Zealand.

"We speak in Samoan to them, they understand but the girls respond in English. When the girls are asked to speak in Samoan they struggle. They don't talk about learning Samoan. I don't know if they are interested"

Parent Tasi explained that her family does attend church but has moved from a Samoan Parish to a Palagi ${ }^{3}$ one, where they have children's programmes that do not involve any reading based activities. One of the reasons for this change is stated below.

"When we first came the kids used to go to Sunday school, we thought they were learning Samoan, like Sunday school in Samoa, but when we go there they are learning in English. So I don't know why they call it Samoan Sunday school”.

It was clear that for Parent Tasi the use of Samoan language is a valued feature and one that she had hoped her children would be engaged in through the church and its literacy activities.

\subsubsection{Parent Fa}

Parent $\mathrm{Fa}$ stated that she would always try to get her children to read aloud to her first. When stuck on an unknown word, her children would be expected to try and say the word by sounding it out. If they made an attempt and it was still incorrect, the word would be told to them. Here guided participation (Rogoff, 1995) is used, as Parent $\mathrm{Fa}$ is scaffolding the learning by supporting her children with pronouncing unknown words together. This pattern of support would be familiar to Parent Fa as it is a reading strategy she experienced herself when learning to read in Samoa, both within the sites of primary school, home and the Pastor's house.

As suggested by Rogoff, "people develop as they participate in and contribute to cultural activities that they themselves develop with the involvement of people in successive generations" (2003, p.52). Applying this concept to this research shows

\footnotetext{
${ }^{3}$ Pagali: a Samoan term for European
} 
that the participants' participation in reading practices during their childhood in Samoa has strongly influenced the way they interact and teach their own children.

When Parent $\mathrm{Fa}$ was asked if any discussions were held at the end of the story being read, the response was no. But Parent $\mathrm{Fa}$ did note that her children ask lots of questions so this could be interpreted as a way of thinking about and comprehending the text being read.

Shared reading was an activity that Parent $F a$ and her children were engaged in. Reading together was used as a way to encourage reading but also to support and guide when necessary.

"We read together, we read books together. She will always read to her dad or me and then we read back together. Her sisters usually read a story to her when she goes to bed".

Here is an example where the personal and interpersonal planes (Rogoff, 1995) can be linked together. The interpersonal plane where Parent $\mathrm{Fa}$ is guiding the participation with her child though reading together and the personal plane where she is encouraging independent practice. This guided participation again provides a structured scaffold for the learner. Parent Fa felt strongly that it was important to make time for reading but that she also needed to tell them to practice. Therefore practice was seen as important to ensure they learnt to read well.

It is important to note that 'practice' as a reading strategy is being strongly promoted by Parent $\mathrm{Fa}$, showing that parents interact with their children in different ways and therefore guided participation (Rogoff, 1995) looks different for different communities. Children "learn as they participate in and are guided by the values and practices of their cultural communities" (Rogoff, 2003, p. 284).

Another home practice being used by Parent $F a$ was interactive reading games like hangman and I Spy. Parent Fa felt this was a good way to learn and encouraged her children to participate, often using her older children to play with younger family members. 
Listening was seen as a key element when learning to read. The idea being that if you listen you will know what you are learning. Speaking was also incorporated into this, being able to answer and ask questions.

"Listen and talk that's what I think. And actually doing something. Like going out, to look at things to talk and write about".

This example could be likened to a language experience based activity. This strategy allows for meaning making by providing opportunities to think about and share experiences that are common and authentic to the child. Language experiences are often used within New Zealand primary school classrooms (Ministry of Education, 2006), for the purpose of extending oral and written language knowledge and usage as Parent $\mathrm{Fa}$ 's response shows.

For Parent Fa's family, reading the Samoan Bible was an important family cultural tradition that has continued in New Zealand. "We have a prayer every evening, that's when we read the Bible - we give the Bible to the kids, everyone reads 2-3 verses".

Parent Fa shared how she supports her youngest child to read the Bible. "I sit with her and she takes ages to read 1 or 2 verses and you have to correct the sounding of some words, but that's alright - she wants to read the bible".

It has been identified previously that Bible reading is a popular activity in many Samoan households, which involves the singing of hymns and reading the Bible (Tagoilelagi, 1995; Tuafuti, 2000) and the concept of apprenticeship (Rogoff, 1995) through the social and cultural influences of organised activities between people.

Tagoilelagi (1995) makes a link between church teachings and parental behaviour, detecting that "strong similarities of teaching methods that are used in the church and home of the children who were observed" (p. 76). This connection can also be made when exploring the home reading practices of these participants. The strategies of shared reading, listening and reciting aloud are all identified and used by the participants. These are teaching strategies that had been experienced in both the Pastor's house and church by the participants as children. 
When talking about Sunday school activities in New Zealand, Parent Fa relayed that both English and Samoan were taught to the children. Activities participated in included reading, answering questions and drawing pictures related to the Bible stories being shared. Parent $\mathrm{Fa}$ discussed how exams, which involved reading Bible stories and answering questions, were held at the end of each year. For the younger children exams are taken orally. The questions were given in Samoan and English, to recognise that for some children their knowledge of the Samoan language was at an emergent level. This exam structure is also followed in Samoa.

\section{White Sunday}

Parent $\mathrm{Fa}$ also shared the importance of White Sunday for her family as a cultural value and tradition as well as a reading practice. The children all learn how to recite a selected Bible verse in Samoan. Lots of practice is involved and there is a strong link between church and home, with the children practising until they can confidently recite their verse independently. The Sunday school teacher selects the verse and parents are expected to support their children in learning and memorising it.

The practices involved in White Sunday provide a clear example of the interconnected nature of Rogoff's three planes of analysis (1995). Participatory appropriation happens when the children practice reciting their selected Bible verses on their own. Guided participation occurs when the adults involved support the children to learn and recite their verses and apprenticeship through church activities that promote and maintain the Samoan culture and language.

During White Sunday, oral performance is valued highly as the children need to be able to recite aloud clearly and independently in front of the whole church congregation. Drama items that involve the children acting out Bible stories also take place during White Sunday celebrations. The children begin this practice at a young age (Duranti \& Ochs, 1993). The expectation is that if a child is unable to perform their verse, they try again the following year.

Parent $\mathrm{Fa}$ shared her own example of this by saying that when her youngest child first tried she was unable to perform her Bible verse. 
"She was like that, she didn't say her verse, she just cried. Most of them cry but they get used to it as they get older".

This shows how literacy learning for Samoan children occurs in conjunction with church-related methodologies of teaching and learning (Tagoilelagi, 1995). When asked why this type of oral performance was so highly valued by Samoan communities, her response suggested the significance and value of oral language achievement alongside religious cultural beliefs.

"I think it is to let them speak, talk and let them listen. Maybe make them understand more of the language, maybe understand more about the Bible stories".

The cultural importance of maintaining the Samoan language is evident here. The church and the religious literacy based activities that the children are involved in, is seen as a way to keep alive Samoan language and traditions.

Both Dickie (2011) and McNaughton (1995) identify the strong connections between the literacy activities that take place at church and home. This provides a "complementary relationship" (McNaughton, 1995) as well as promoting similar cultural values between the church and family. Church literacy is based on rote learning and oral presentation of biblical texts, which are read and memorized (Duranti \& Ochs, 1993). This emphasis on reading aloud and memorisation happens both at church, Sunday school and home and is seen as strength by Samoan communities (Duranti \& Ochs, 1993; Dickie \& McDonald, 2011).

\subsubsection{Parent Tolu}

Parent Tolu felt that her level of English at times made it hard for her to support her children with learning to read. Commenting that when her daughter was young "I helped her a little bit but she understands more than me now". Her older children often took on a supportive guiding role with younger family members and were used to help out with reading practice and homework. The role older siblings play in supporting their younger siblings with reading was also mentioned by Parent Fa. 
Dickie \& McDonald (2011) noted that older siblings were involved in reading to younger family members as well as asking and responding to questions about the text.

Like Parent Fua, Parent Tolu identified that she felt it was important to encourage her children with reading by reading together. Reading together happened when one of her children bought a school reader home. It was evident from her response that reading together involved repeated practice as well as enjoyment of text.

"About 4 or 5 times after school, and then before she goes to bed, I say come and read next to me, I want to hear you. She sometimes whispers, so I say read louder and she's loud to my ears".

"And sometimes she says read together, we read plays and I'm the mum, sometimes I am the father and she laughs (dad voice used). Yeah we love to read out loud together".

The supportive nature of reading together as expressed by Parent Tolu was not limited to this participant. For all the participants interviewed, there appeared to be a strong emphasis on learning together and reading is often a joint activity that involves a number of others.

Parent Tolu identified Sunday School as a place to further develop reading acquisition through reading and reciting Bible stories. The children answered questions about the Bible stories being read, often in both Samoan and English. Again there was recognition that for a lot of children who are born in New Zealand their knowledge of the Samoan language is limited so the English Bible is used too. Parent Tolu expressed that her children did well at Sunday school and she felt that it was an important way for them to develop their reading skills and follow Samoan cultural values and tradition.

"She is very good at Sunday school, she always comes first. She spells the words too, five big words to learn for homework and you have to come back and spell them, in Samoan" 


\subsubsection{Parent Lua}

Parent Lua was aware that how she learnt to read in Samoa was different to what her children were experiencing at school in New Zealand. Out of all the participants it was evidence that she had had the most interaction with her children's teachers.

"I need an idea from my son's teacher so I can fit myself in to help him, so I'm not confusing him, so I can help keep up the good work from the teacher'.

Here Parent Lua shows an awareness that there are cultural differences across communities in how children are taught to read (Rogoff, 2003). Parent Lua is also acknowledging that she believes it is important for her children to get consistent messages from home and school.

When listening to her children read at home, Parent Lua specified that it was imperative for them to learn the words. She felt it was vital to see if her children were reading from the pictures or reading the words accurately. One strategy used was to cover the picture at times.

"So sometimes I will cover the picture, and say you have to read from the word. I want her to know how to spell 'is, the, little'. When I cover the picture she can get stuck with the word, so I release the paper and she has another look at the picture".

It needs to be noted that this technique for early readers would not been seen as an effective reading strategy in a New Zealand classroom (Ministry of Education, 2006), so despite Parent Lua engagement with school, her interpretation of practice may have lead to this misunderstanding.

Another reading strategy used could be identified as word chunking. Parent Lua provided this explanation.

'Say it was the word 'sit', I would cover the first letter and look at 'it' and say what is the first letter, ok what the name, what's the sound of it. Then sound all the words together".

This is an interesting example as it is a word attack reading strategy that would be seen as useful and effective by New Zealand teachers (Ministry of Education, 2006). Where as the practice of covering the picture for an emergent or early reader would 
not, as children at this early stage, rely on using the pictures to support them make and check word predictions.

When identifying what skills are important when learning to read being able to say the words correctly and practising through repetition come through as paramount for this participant.

Parent Lua made a connection to oral performance, a strong cultural value for Samoan communities that has been identified previously, "when you read aloud you need to be able to use the right tone, and the pronunciation is really important, saying the words accurately".

This is seen as a strong measure of being able to read well for these participants, that their children were able to read aloud accurately and clearly. This type of oral language learning can be connected to the Tauloto (performance) routine that is used both within the Pastors' house and church in Samoa (McNaughton, Amitanai-Toloa \& Wolfgramm-Foliaki, 2009). This way of learning was well known to all the participants interviewed.

Like Parent Fa and Parent Tolu the importance of oral performance is mentioned when reading with her children at home. "Read it aloud, in the right tone-pronounce the word right, then after that repeat the story again"

Here again is an illustration of the strong link between home and church literacy practices. The cultural value placed on oral performance through recitation and repetition is viewed as a key component for reading acquisition. These parent participants have been apprenticed into these reading practices (Rogoff, 1995), which are then passed down to their own children.

Like Parent $\mathrm{Fa}$ interactive reading games were also being used to help with learning to read. "I like reading with my kids. Games like I spy. We play together, reading games". 
Listening was also emphasised as an importance element for learning to read. Parent Lua shared an example of what she expected her children to be doing when being read to.

"I want her to sit and listen - to concentrate, I don't want her to do anything, just sit and listen so she doesn't miss what the story is about".

But listening went the other way too. Parent Lua shared that as an adult she need to be able to listen actively to what her children were sharing with her. So listening is a reciprocal, interactive process.

It's important to listen to the kids, to share new ideas and thoughts. It's like making a new story.

From the transcripts, Parent Lua was the only participant who clearly discussed understanding of the text being read. While examples can be found in the responses of the other participants, comprehension of text was not something that was discussed by them when recounting home reading practices.

Here Parent Lua provides evidence to show that reading for meaning is seen as an important component when learning to read.

"It's important that they understand, if they are interested in the story they will ask questions - don't stop them, let them ask.

Don't ask any questions while they are reading, then after ask to check if they understand what the story is about. They need to know about the story".

The Samoan Bible was used by Parent Tolu's family to keep alive the Samoan language and traditions.

"The bible every evening, every Sunday we will practice a verse. I will read, and my children will follow".

Parent Tolu commented that the pronunciation of Samoan words was difficult for her children and she was aware that she needed to speak more slowly, saying "sometimes I speak fast in Samoan and my children cannot understand me".

For Samoan communities the maintenance of their language is extremely important (Dickie, 2011) and it is clear that the Bible plays a key role in this. As indicated in earlier findings, the reading of it is a family affair and a strongly valued cultural practice. Rogoff's community plane (1995) can be applied here, where individuals are 
able to take what they have learned in family and community sites and apply it to new situations. The new situation of living in New Zealand and wanting to ensure that the strong cultural values around language and religion continue from the participants and their families in evidence through the transcript responses recorded.

\subsubsection{Parent Lima}

Parent Lima was the most recent immigrant to New Zealand amongst the participants interviewed and a number of her children had attended primary school in Apia before leaving Samoa. It was clear from Parent Lima's responses that she held strong beliefs around her children being independent readers.

The reading practices being employed by Parent Lima at home illustrate the interconnectedness of the three planes of analysis (Rogoff, 1995). Initially, Rogoff's personal plane is in the foreground, where the children are expected to engage independently in a cultural activity applying what they know about reading.

First I say go and read your own book. I get them to have a look first, even if they could not read it - I say have a look at the pictures, so you have an idea of what's in the book.

After her children initially engaged with reading independently, Parent Lima then sits with her children and listens to them read. Here guided participation (Rogoff, 1995) happens as Parent Lima shared that she only intervenes when they are struggling to say an unknown word, and at this point there is encouragement to attempt independently.

"only when they are struggling then I say try, look at the letters, make the sound - try, try. So if I heard they are trying that good, at least they are trying. Then I will jump in and say it correctly. Then they will go back and get them to read it again".

Parent Lima's emphasis here is on decoding, sounding out the words until they are mastered correctly. Encouraging children to attempt independently using a range of cross checking strategies before appealing is an effective strategy that would be actively encouraged during guided reading lessons at school (Ministry of Education, 
2010). But it is also evident here that decoding and practising are the dominant reading techniques being employed by this participant.

The idea of developing independence through not wanting to 'spoon feed' her children came up again, when Parent Lima discussed teacher-student ratio in Samoa. She felt that a teacher's time was restricted when there was a high student ratio and that it was important that children learnt to do things on own their own and therefore take responsible for their learning. So while teacher-student ratios in New Zealand classrooms are lower than in Samoa, Parent Lima still held the cultural belief that her children needed to learn how to be independent learners. This belief has been shaped by her knowledge of how classrooms in Samoa operate.

When Parent Lima was asked if her and her children discuss the books being read together, her response was as follows, sometimes I do this, after they have read it I will grab it and read it aloud. Then ask questions like what was that book about? what was the story about? If they can't respond, then I know they can't get the meaning so I will try to explain what it's about to them".

This is example of using questioning to gage a child's comprehension after reading a new text, a strategy that aligns with New Zealand school practice (Ministry of Education, 2006).

Like Parent Tolu and Parent Lua reading the Samoan Bible as a family was seen as highly valued activity by Parent Lima. Again it was an opportunity for her and her husband to share and teach the Samoan language to her children.

"We will read the bible. I or my husband will be the leader. Then my children will read. But my oldest son goes fast, because he is fluent and the little ones are slow. But I give them time. It's important to us as a family".

Bible reading also provides the family with reading opportunities to read aloud through reciting verses, pronounce and decode words correctly. "Sometimes we read all together, and sometimes we take turns, and I help them with pronouncing. The little ones are still practising”. 
When Parent Lima shared her thoughts on the importance of helping her children with reading at home, it was evident that she valued and recognised the importance of supporting her children learn to read.

"It a big thing to me, I have to help them. Even though I know school here in New Zealand is really helpful and that reading is the key to other things. With my kids if I don't do reading with them, I feel guilty. I feel it is very important. It's something I have to do".

\subsubsection{Some common threads}

When identifying the similarities between these parent participants' responses, there are some clear beliefs that are shared by all. In the New Zealand context, the importance of reading together through shared reading was valued by all participants and seen as an important way to support their children with practising their reading. It was also obvious that shared reading was used to promote an enjoyment of reading, through the participants being engaged in reading with their children regularly. For some of the participants reading together would involve a number of family members, often older siblings, this could be seen as a way to promote more practice and repetition. Shared reading was not just restricted to home school reader, with the Bible playing a essential part and other reading materials like library books, books from older siblings and general household text types.

Reading together was also connected to oral performance through the importance of being able to recite and pronounce correctly when reading aloud. This Tauloto performance routine is also practised in church literacy, therefore showing a strong link between home and church. This is in alignment with Tagoilelagi's (1995) research finding that the Tauloto routine was the dominant way of learning when researching what storybook and bible-reading activities Samoan families were in involved in Samoa and New Zealand. "The adults have been taught the same way to read and have now transmitted such methodology to their children" (p. 75). Listening was a reading strategy used by the participants to promote and ensure concentration and understanding of what was being reading. 
The main role for parents when reading with their children that was identified by all the participants was ensuring correct word pronunciation. This was achieved through supporting their children to sound out words or modelling the correct pronunciation for them. This strong emphasis on pronunciation of words through telling and modelling shown in these findings supports the research compiled by Amitanai-Toloa (McNaughton, Amitanai-Toloa \& Wolfgramm-Foliaki 2009). Amituanai-Toloa found the key strategies being used to support their children were look and say the word, repetition, recitation and rote learning. Amituanai-Toloa also noted that influencing how a group of Samoan mothers guided their children when listening to them read school readers, were their cultural beliefs around being Samoan and their own childhood experiences of being taught at school or home. Dickie and McDonald (2011) also noted that correct pronunciation and accuracy of content were important when researching literacy practices in church and family sites within New Zealand.

Another common element that was present in all the participants' responses was the strong role of Sunday school in reading acquisition and maintaining traditional Samoan social and cultural values and beliefs. While Parent Tasi's children were not attending a Samoan Parish, her beliefs around language and culture indicated that this too was important for her.

Finally home Bible reading was a common practice for four out of the five participants. Reciting Bible verses, as a family was a way to support reading acquisition and cultural beliefs and values (Tagoilelagi, 1995; Tuafuti, 2000). Bible reading was also identified as a way to keep the Samoan language alive for these participants and their children.

It is critical to consider the impact of these social and cultural values and practices that are being implemented by these Samoan born parent participants. Knowledge of these values and practices needs to used to help understand and value the home reading practices that are happening for Samoan children. As stated by Tagoilelagi (1995) the "conditions of socialization and cultural influences which determine the ways in which Samoan children have access to specific reading patterns" (p. 1) need to be understood. 


\subsection{Section 2: The children's responses to identify home reading practices}

This section reveals the participants' children's ideas on reading practices at home. The interview transcripts confirm that the parent participants are employing the reading strategies that they themselves identified earlier when helping their children with reading at home. It also highlights the role of siblings in supporting home reading practices.

When analysing the participants' children's responses it was apparent that older siblings played an important role in guided participation (Rogoff, 1995) at home. This reading support took the form of helping younger children to sound out words. The children also identified helping to sound out unknown words, as the main form of guidance given by parents as well. This is a similar finding to Dickie and McDonald (2011), who identified that older siblings were often responsible for introducing school ways of learning, often acting as teachers.

When the children were asked if any questioning about the text being read happened three out of the five stated no, citing that they just read the story. Two children respond that sometimes someone would ask them questions about what happened in the story. There was only one example where the meanings of words were discussed. This pattern of reading support is backed up by the parent participants' responses where emphasis is placed strongly on accurate decoding and word pronunciation.

It was clear that all the children saw their parents and siblings engaged in reading activities. Time to read together was valued and practised by all the families involved in this research. Three of the five children discussed how their mothers would read magazines and newspapers with them and talk about the content together. Two of the children were witnessing their older siblings studying for college or university. Reading games and using the computer to play games and search for information was identified as well.

For these children, like their parents the Bible was seen as an important family activity as well as an opportunity for reading practice. The children shared their experiences of reading the Bible at home and Sunday school. They discussed being 
tested every year, which involved learning Bible stories and being questioned on them as well as spelling practice. Two children shared about having to read the Bible without looking and having to memorise, saying this was hard to do and involved a lot of practice.

\subsection{Section 3: Parent knowledge of school reading practices in New Zealand}

During the first Talanoa sessions, each parent participant was asked to share what they knew about how learning to read happens in New Zealand schools and what their children shared about school reading practices with them. The participants were also asked to identify what differences there were between learning to read in Samoa and New Zealand.

Analysis of the participants' responses showed that for this group of Samoan parents, little was known about how their children were taught to read at school. All five participants stated that they had no real knowledge of how reading was taught within New Zealand schools.

The reasons for this knowledge gap could be attributed to two factors. Firstly, it was evident that there was limited correspondence between teachers and these parent participants. Only two out of the five participants had observed in their child's classroom, with both only recalling one or two occasions when this took place. One

participant had recently completed the school's run Reading Together programme (Biddulph, Biddulph \& Biddulph, 1982) but this had happened after the Talanoa sessions had been taken. One of the participants stated that she had regular talks with her child's classroom teacher due to concerns about progress being made in literacy. The other participants noted that they attended parent-teacher interviews but did not have regular contact with their child's teacher or school. It can also be assumed that the school would be undertaking twice yearly written reporting to parents. Due to this limited correspondence it can be concluded that there were few experiences for the parents to develop knowledge about the reading practices in their children's classrooms in New Zealand. 
The second factor limiting the parents' knowledge of school reading practices relates to their perception of the teacher's role. Three of the participants stated that if their children were having no problems at school and appeared happy, the teacher was left to teach. As noted by Crozier (2000), teachers are seen as the experts with the expectation that teachers would inform them on progress or if any problems arose. McNaughton (2001) identifies that for Pasifika parents there is often a level of trust in teachers to educate their children. That educating is the teacher's role and one that a parent does not need to intervene in. Crozier (2000) notes that for some parent groups there is more willingness to accept teacher judgement and play a less passive role in teacher-parent relations.

It was clear that the participants' children were sharing and discussing what they did at school when asked by their parents. However, the information being given was activity based rather than learning or skill based, where their children would share the subjects or topics they were participating in rather than the learning that was being engaged in. The following parent participant responses demonstrated this, "She will always talk about when her teacher has praised her for something, in her reading or writing"

"She will talk about her trips, like going to Te Papa. Not really about what she is learning to do"

(Parent Lua)

"Everyday I ask them about school, they tell me what they do - like maths, reading, just the book and what it is about"

(Parent Tasi)

Therefore the information that this group of parents were receiving from their children was not giving them any clear understanding of the reading practices or skills being taught in New Zealand classrooms. This can be viewed as another factor that is contributing to how school reading practices are being interpreted, as the reading skills and strategies being used by the teachers are not being explicitly shared between home and school. 
These research findings regarding parents' knowledge of New Zealand reading practices align with other researchers investigating Pasifika parents and schooling for their children. Cahill (1996) noted "parents' lack of experience of the NZ education system and how it works compounds their difficulties in understanding and engaging positively with it. Theirs is an interpreted knowledge acquired second-hand from their children" (p.67). When investigating Pasifika students' perceptions on what supports or hinders their reading achievement, Tufulasi Taleni, Parkhill, Fa'afoi and Fletcher (2007) identified that Pasifika parents want to best support their children but do not always know how.

When attempting to explore further the participants' understandings of the reading skills being taught in New Zealand, during the second Talanoa sessions, it was evident that the participants felt there were clear physical, practical differences between schools in Samoa and New Zealand. For instance based on the participants' own experiences in Samoa, schools had higher student/teacher ratios, fewer resources, fewer independent activities for the children and no specialised assistance. (See Appendix D: Parent Summary Lists for further examples).

But despite their limited understanding of school reading practices three out of the five of participants felt that the key aspects of learning to read would be similar for teachers in Samoa and New Zealand. Therefore it could be concluded that the participants' social and cultural beliefs around the importance of oral language, rote learning and decoding as teaching strategies when learning to read, were influencing their interpretations of what would likely be happening in New Zealand classrooms.

There were some examples amongst the participants' responses, where connections had been made that showed how physical differences, like class size and resources, would be expected to have an impact on a teacher's actions. For example Parent Lima, talked about the impact a lack of reading books had on how a teacher could teach reading, because of this a student would have limited opportunities to read independently.

You can't read yourself - the teacher has to read to you and you have to listen. If there was a long word, she would write it on the board, to spell and write it and learn 
it. You have to write the word many times. Not like in New Zealand where all the kids have their own books. (Parent Tolu)

Another example can from Parent Fua, when discussing how her children in New Zealand get extra learning support.

In Samoa if you are not good at English, you have to come in the class and catch up and listen to the teacher - there is only one teacher. We don't have teacher aides, ESOL lessons, extra help, we don't have that.

Here Parent Fua is referring to New Zealand's ESOL funding programme (Ministry of Education, 2008), where English Language Learners can be identified and provided with extra support to assist their learning of English at school.

From the limited data collected in this thesis, it is difficult to provide a definitive explanation of why the majority of the participants felt that school reading practices would be similar in Samoa and New Zealand, but it seems clear that cultural values and beliefs play an important role in the assumptions that are being made by these parents about school reading practices within New Zealand. The social and cultural values that have been apprenticed through their own experiences and memories of learning to read in Samoa are playing a key role in their understandings and interpretations of reading strategies and practices.

Despite this, research does indicate that there are clear differences between different cultural communities regarding how reading practices are viewed and implemented. According to Tuafuti (2000) Samoan literacy is strongly associated with cultural traditions and family and church expectations. Literacy learning and living a communal way of life based on Fa'asamoa ${ }^{4}$ is interwoven for Samoan communities. Reading programmes in most Pacific Island schools tends to emphasize skill acquisition and therefore has a more functional and restricted view of literacy. Tuafuti (2000) goes on to note that these expectations are different from literacy based programmes within New Zealand schools.

\footnotetext{
${ }^{4}$ The Samoan Way and describes the socio-political and cultural way of life for Samoan people
} 
Hamel (2003) adds to this by stating that there are clear differences between the literacy experiences that occur in home and the ones constructed by teachers for classroom teaching. Hamel argues, "school literacy is only one type and can be very different from the kinds of literacies that naturally occur in homes and communities" (p.20). Gregory (2007) advocates for schools identifying these differences but also seeing them in a positive light rather than taking a deficit approach to home reading practices.

\subsection{Connections or Disconnections between home and school reading practices?}

A key aim of this thesis was to establish if there were connections or disconnections for this group of Samoan parents between home and school reading practices. From the findings it is appear that there are a number of disconnections being experienced. The impact of this will be discussed further in Chapter Six, where conclusions and recommendations are established. 


\section{CHAPTER SIX: CONCLUSIONS AND RECOMMENDATIONS}

\subsection{Introduction}

This research set out to investigate how the social and cultural values and experiences of learning to read influence the home reading practices employed by Samoan parents in New Zealand. While only a small group of Samoan parents were involved in this research, it has value in informing teachers of possible strengths in home reading practice that can be built on and where there may be misunderstandings. The aim was to gain knowledge of the participants' own experiences and understandings of learning to read as children in Samoa, then identify what reading practices and strategies were evident across the literacy sites of the Pastor's house, primary school and home. From this the Talanoa findings revealed that the participants were using a number of the identified reading strategies with their children during home reading practices in New Zealand.

In addition to identifying what reading practices were being employed at home, the parent participants were also asked to share their knowledge of school reading practices. From the participants' identified home reading practices and their knowledge of school practice, inferences were made about connections and disconnections between home and school for these parents and their children in New Zealand.

By using a socio-cultural perspective (Gregory, 2007; McNaughton, 2002; Nieto, 2010), the intention was to identify and value the meaningful home reading practices being used by these Samoan families and to explore and gain understandings of the influence that social and cultural values have on the practices being used, and the possible impact of this on home-school connections and disconnections. 


\subsection{Summary of findings}

The overall findings show that for these Samoan parent participants there are differences between home and school reading practices. These differences are based on the social and cultural values and beliefs formed from their own experiences of learning to read in Samoa. The experiences have been shaped within the literacy sites of the Pastor's house, primary school and home, where cultural interactions have occurred on a personal, interpersonal and community level (Rogoff, 1995).

It was clear from the findings that the reading practices and strategies these participants had experienced in Samoa when learning to read as children, were now being passed down to their own children. Decoding and rote learning through memorization and practice along with a strong emphasis on recitation were the key reading strategies being employed by the participants with their own children. These were reading practices and strategies that they had experienced and been apprenticed into as children and young adults, that had been learned through interactions with their families, teachers, pastors and other community members (Rogoff, 2005).

Early reading acquisition took place at the Pastor's house for the participants. The reading activities here were often structured in a cooperative way that allowed the Pastor to guide and support, as the children learnt the Samoan alphabet and Bible verses through repetition and recitation (Duranti \& Ochs, 1993; Tuafuti, 2000). At the primary school level, the teaching strategies being used were similar to those being used by the Pastor and often his wife. The teacher would use the strategies of decoding and rote learning to teach reading. The primary resource and tool used for reading practice at home was the Bible. Bible reading was a regular family practice that incorporated oral performance with a focus on correct word pronunciation and rote learning through practice and repetition. In all three literacy sites reading acquisition was strongly influenced by Fa'asamoa, learning about the cultural beliefs and values of the Samoan way of life.

In a New Zealand context, when describing the home reading practices used with their own children, again there were clear social and cultural beliefs about reading 
that were valued by all the participants. Shared reading through reading together was seen as a way to help their children practice in a supportive way and as adults it enabled them to provide the correct model when necessary. Reading together was also connected to oral performance. By encouraging their children to read aloud, the parents were able to monitor for correct tone and pronunciation of words.

It is important to note that while the children of these participants were not involved in the type of learning activities experienced at the Pastor's house like their parents, the role of the church in reading acquisition was still significant. Attending church and Sunday school was a cultural value and tradition being continued in New Zealand for all of the participants and their children, and a key purpose of this was to promote the Samoan way of life, Fa'asamoa, as well as develop their reading skills. For all the participants their children attending Sunday school was highly valued to ensure learning about cultural and religious beliefs and maintenance of the Samoan language. Home reading of the Bible was another way that these participants developed their children's reading ability and cultural knowledge.

As identified in earlier chapters it is important to recognise and acknowledge that the values underpinning school reading practice in Samoa and New Zealand are different. In Samoa, all students through the strategies of rote learning and decoding gain core reading knowledge. This bottom up approach, as described in Chapter Two, emphasises skill acquisition and therefore a more functional view of literacy (Tufulasi Taleni et al, 2007; Tunmer, Chapman \& Prochnow, 2004). In New Zealand, the approach can be defined as a more co-operative, integrated learning process (Cahill, 1996; Ministry of Education, 2006).

In spite of this limited understanding of school practice, there was still the perception that while there were physical differences between classrooms in Samoa and New Zealand like access to resources and larger class sizes, most participants believed that the teaching of reading would still be based on strategies and skills that were similar to those used in Samoa. It was therefore concluded that the participants' social and cultural beliefs around the importance of oral language, rote learning and decoding as 
teaching strategies when learning to read, were influencing their interpretations of what would likely be happening in New Zealand classrooms.

\subsection{Implications for teachers and schools}

This thesis has identified some key implications for primary school teachers of Samoan children. It is clear that for these participants their cultural experiences and values have strongly influenced the home reading practices they employ with their own children. In addition to identifying that the participants were using the cultural practices of Samoan literacy (Duranti \& Ochs, 1993; Duranti, Ochs \& Ta'ase, 2004; Tuafuti, 2000), the findings also showed that they had limited knowledge of school reading practices in New Zealand. There are different literacy experiences happening between home and school for these parent participants and their children. This has real implications for all involved - parents, schools and policy makers. This research adds to understandings around differences in home and school reading practices, like others it highlights that there are clear dissimilarities between practices for different cultural groups (Crozier, 2000; Dudley-Marling, 2009; Heath, 1983).

The research findings reinforce that there are disconnections between the home reading strategies being used and school practice. It has been established that the reading practices guiding Samoan literacy are strongly based in oral language, rote learning and decoding (Duranti \& Ochs, 1993; Tuafuti, 2000). However this contrasts with what effective reading practice in New Zealand classrooms are based on, where the teacher is providing strategic instruction in decoding, making meaning, and thinking critically (Ministry of Education, 2006).

It was evident from the participants' responses that there was limited correspondence between home and school, which meant that their opportunities to discuss and learn about school reading practices, were minimal. This obviously has implications for home-school connections as understandings of each others' reading practices are not being heard or discussed. Secondly, the perception of the teacher's role for these Samoan parents was similar to what has been noted by other researchers, in that it is the teacher's role to educate and that as parents they do not need to intervene (Crozier 
2000; McNaughton, 2001). Gorinski and Fraser (2006) cite that cultural differences can create misunderstandings that impact negatively on parent engagement. How teachers and schools address this is challenging but through better understandings of the cultural beliefs and values that influence home practice, this can be worked on.

For these participants the alignment between home and school practices was minimal. It therefore needs to be considered what impact this has on learning to read for the children involved. How do teachers and schools use the knowledge gained from parents regarding their own reading experiences and practices to support their students make greater connections between home and school learning. It is important to note that there is value in some of the strategies being used by this group of Samoan parents, like shared reading and oral performance. The implication here is that ways need to be found to empower and learn from Samoan parents to create a sense of joint collaboration and connection making so as to not underestimate the role parents can play (Goldenberg \& Coleman, 2010).

As noted in Chapter Two, there have been Ministry of Education initiatives (1982, $1987 \& 2005)$ that have shown to be effective in supporting parent engagement and home-school connections and have focused on implementing school practice into the home. This thesis has aimed to add to this but also place a stronger emphasis on what can be learnt from home reading practices and the experiences of Samoan parents in order to inform teachers and schools. It can not just be about working out what schools need to share with parents regarding reading practices but what can be learnt and valued from home practices. "Teachers are urged to adjust their teaching strategies so that they better match the cultural patterns and family literacy practices of their students" (Tunmer, Chapman \& Prochnow, 2004, p. 140).

A critical factor shown by this thesis is that it is essential that schools have a greater understanding of what Samoan parents bring to their children's schooling. As pointed out by Cahill (2006) few New Zealand teachers have an "in depth knowledge of the values inherent in Samoan society and culture" (p.69). There are clear cultural values and practices that are being implemented by Samoan parents that teachers and schools 
need to be able to understand and utilise in ways that add to student learning and achievement.

It needs to be a two way process that empowers both New Zealand teachers and Samoan parents. Schools need to be able to learn from and see the value in the cultural values and beliefs that Samoan parents bring to reading practices through greater parent communication and the sharing of experiences. It is clear that primary school teachers and educators need to understand in better ways what children and their families bring to classrooms as a number of researchers have indicated (Cairney \& White, 1999; McNaughton, 1995). As stated by Cairney and White (1999), by the "development of shared understandings we need to understand more about the various ways in which parents and children respond to school literacy practices" (, p. 84).

It is important to acknowledge that families have a right to access the forms of literacy recognised at school. Parents need to know about and have access to resources and strategies to practice at home. Schools have a responsibility to connect the literacies of home and school (McNaughton, 1995). It is just as essential that teachers and schools acknowledge the impact that cultural beliefs and practices have for parents and their children. We do not what it to be a one-way model where "teachers share expectations for reading at home with parents and parents do their best to comply" (Dudley-Marling, 2009, p. 1741).

\subsection{Recommendations for teachers, schools and policy makers}

Establishing positive home-school relationships as a means to enhance student learning and achievement is not new (Biddulph et al, 2003; Ministry of Education, 2007). However what is new in this thesis is the finding that strong cultural beliefs and values that guide and influence home reading practices need to be considered and better understood by teachers and schools. It is clear that effective home-school partnerships cannot be based on disconnections around reading practices between home and school. There is a need to understand the social and cultural differences in reading practices or there will continue to be a gap in the values and experiences 
between home and school for Samoan communities that will act as a barrier to equal engagement with school.

Another recommendation would be if teachers and schools are going to actually value what has been stated in to the Ministry of Education's Pasifika Education Plan 20132017, there needs to be a stronger commitment to investigating what home reading practices are for Samoan communities within New Zealand. This is an education plan that aims to "put Pasifika learners, their parents, families and communities at the centre of the education system, where they can demand better outcomes" (2013). Stating that the New Zealand's education system must work better for Pasifika learners (Ministry of Education, 2013).

It is not as simple as just stating that schools need to be more engaged with their Pasifika communities. As New Zealand moves towards a more inclusive education system it is important to consider how diversity and cultural differences are understood and valued. This would require further teacher education to support teachers and schools in seeing the value and importance of gaining knowledge of home reading practices. Teachers and school would need to be aware of the role greater connections between home and school could play in supporting children with learning and achievement. If teachers and schools see school reading practices as the only way then open, collaborative dialogue is limited. This type of correspondence does not provide opportunities that allow cultural communities and schools to come together and share similarities and/or differences in reading practices. It is clear that continued dialogue is need. The Talanoa structure employed during this research allowed for collaborative communication to take place. The engagement of these Samoan parents provided an opportunity for the voice of parents to be heard and furthermore, validated their teaching and learning approaches and practices.

The Talanoa structure if established well allows for relationship building and open dialogue to occur. Greater and on-going Talanoa between the teachers, parents and students in schools would be beneficial in assisting to develop knowledge of reading practices. There is a clear link here to the Pasifika Research Guidelines (Anae et al, 2001) that promotes ownership and consultation. It is important to acknowledge and 
find ways to address the power relationships involved when working with Samoan parents, teachers and schools. There is a need for co-construction, to identify how literacy knowledge and practices can be jointly constructed. There needs to be a willingness on the part of teachers, schools and parents to know more about the home settings their students come from.

Gorinski and Fraser (2006) advocate for a change of thinking and practice in schools, "from a monocultural to a multicultural lens, in order to promote effective parent community - school engagement in Pasifika contexts" (p. 32). A point reinforced by Rogoff (2003) who states that different cultural communities can learn from each other without giving up what they value has not be developed fully (p.356). This is huge challenge for teachers and schools but one that needs to be identified and address to ensure equal opportunities for all students within the New Zealand education system.

Finally, The Pasifika Education Plan (2013) clearly states that it aims to achieve optimum learning by promoting closer alignment and compatibility between:

- the learner's educational environment, and

- their home and/or cultural environment

This research has intended to question this, for there to be closer alignment, there needs to be closer understandings between home and school practices. To engage parents as partners in the learning therefore achieving greater educational success (Goldenberg \& Coleman, 2010). It will be interesting to see how this sits within the expectations being placed on teachers and schools regarding National Standards.

\subsection{Thoughts for Future research}

Any further research into home and school relationships through sharing of knowledge and practices is critical if continued gains are going to be made into Pasifika learning and achievement. Educational collaboration comes when cultural values and actions are acknowledged, shared and valued. 


\section{REFERENCES}

Alton-Lee, A. (2003). Quality teaching for diverse students in schooling: Best evidence synthesis. Wellington: Ministry of Education.

Amituanai-Toloa, M., McNaughton, S., Kuin Lai, M. \& Airini. (2009). Ua Aoina le Manogi o le Lolo: Pasifika Schooling Improvement Research - Final Report. Auckland: Research Division, Ministry of Education.

Anae, M., Coxon, E., Mara, D., Wendt-Samu, T., \& Finau, C. (2001). Pasifika Research Guidelines: Final report. Auckland: Research Division, Ministry of Education.

$\mathrm{Au}$, K. H. (2003). Multicultural factors and the effective instruction of students of diverse backgrounds. In A E Farstrup \& S J Samuels (Eds.), What research has to say about reading instruction ( $3^{\text {rd }}$ ed., pp. 394-410). Newark, DL: International Reading Association.

$\mathrm{Au}, \mathrm{K} . \mathrm{H}$. (2011). Literacy achievement and diversity: keys to success for students, teachers and schools. New York: Teachers College Press.

Biddulph, F., Biddulph, J., \& Biddulph, C. (2003). The Complexity of Community and Family Influences on Children's Achievement in New Zealand: Best Evidence Synthesis Iteration (BES). Wellington: Ministry of Education.

Bruning, R.H., Schraw, G.J., \& Ronning, R.R. (1999). Cognitive Psychology and Instruction: Third Edition. USA: Prentice Hall.

Cahill, F. (2006). Crossing the road from home to secondary school: A conversation with Samoan parents. Waikato Journal of Education, 12, 57-72.

Cairney, T. and White, N. (1999). "Winners and Losers" in the Development of Home-School Literacy Partnerships: An Analysis of Discourses of Power. English in Education, 33(3), 82-102

Conteh, J. \& Kawashima, Y. (2008). Diversity in family involvement in children's learning in English primary schools: Culture, language and identity. English Teaching: Practice and Critique, 7(2), 113-125.

Creswell, J.W. (2003). Research design: qualitative, quantitative, and mixed methods approaches. Thousand Oaks: SAGE.

Creswell, J.W. (2013). Qualitative inquiry and research design: choosing among five approaches. Thousand Oaks: SAGE.

Crozier, G. (2000). Parents and schools: Partners or protagonists? Stoke-on-Trent: Education Press. 
Dickie, J. (2011). Samoan students documenting their out-of-school literacies : An insider view of conflicting values. Australian Journal of Language and Literacy, 34 (3), 247-259.

Dickie, J. \& McDonald, G. (2011). Literacy in church and family sites through the eyes of Samoan children in New Zealand. Literacy, 45(1), 25-31.

Dudley-Marling, C. (2009). Home-School Literacy Connections: The Perceptions of African American and Immigrant ESL Parents in Two Urban Communities. Teachers College Record, 111(7), 1713-1752.

Duke, N.K., \& Purcell-Gates, V. (2003). Genres at home and at school: bridging the known to the new. The Reading Teacher, 57(1), 30-37.

Duranti, A. and Ochs, E. (1993). 'Literacy instruction in a Samoan village', In B. Schieffelin and P. Gilmore (Eds.), The Acquisition of Literacy: Ethnographic Practices. pp. 213-232). New Jersey: Ablex.

Duranti, A., Ochs, E. and Ta'ase, E.K. (2004). 'Change and tradition in literacy instruction in a Samoan American community', In E. Gregory, S. Long and D. Volk (Eds.), Many Pathways to Literacy: Young Children Learning with Siblings, Grandparents, Peers and Communities. (pp. 159-170). London: Routledge Falmer.

Education Review Office. (2008). Partners in Learning: Schools' Engagement with parents, whanau and communities. Wellington: Education Review Office.

Fletcher, J, Parkhill, F, Fa'afoi, A \& Morton, M. (2006). Poto He Anga: Collaboration and Consultation in Pasifika research. Qualitative Research Journal, 6(1), 36-50.

Fletcher, J., Parkhill, F., Fa'afoi, A., Tufulasi Taleni, L. \& O’Regan, B. (2009). Pasifika Students: Teachers and Parents Voice Their Perceptions of What Provides Supports and Barriers to Pasifika Students' Achievement in Literacy and Learning. Teaching and Teacher Education: An International Journal of Research and Studies, 25(1), 24-33.

Ferguson, P.B., Gorinski, R.; Wendt-Samu, T \& Mara, D. (2008). Literature review on the experiences of Pasifika learners in the classroom. Wellington: Research Division, Ministry of Education.

Gorinski, R. \& Fraser, C.(2006). Literature review on the effective engagement of Pasifika parents and communities in education. Wellington: Research Division, Ministry of Education.

Gregory, E. (1999). Myths of illiteracy. Written Language and Literacy, 2(1), 90-109.

Gregory, E. (2007). What counts as reading and learning outside of school? and with whom? how? and where? In Bearne, E. \& Marsh, J. (Eds.), Literacy and Social Inclusion: Closing the Gap (pp. 41-52). Stoke-on-Trent: Trentham. 
Goldenberg, C. \& Coleman, R. (2010). Promoting academic achievement among English learners: a guide to the research. USA: Corwin.

Hamel, E.C. (2003). Understanding Teachers' Perceptions of children's home language and literacy experiences. The Professional Educator, $X X V(2), 9-21$.

Heath, S. B. (1983). Ways with words: Language, life, and work in communities and classrooms. New York: Cambridge University Press.

Johnson, B. \& Christensen, L. (2012). Educational Research ( $4^{\text {th }}$ Edition). USA: Sage.

Kay, A.M, Neher, A., \& Hall Lush, L. (2010). Writing a Relationship: Home-School Journals. Language Arts, 87(6), 417-426.

Ladson-Billings, G. (1994). The dreamkeepers: successful teachers of African American children. San Francisco, USA: Jossey-Bass Publishers.

Love, K. \& Hamston, J. (2003). Teenage boys' leisure reading dispositions: juggling male youth culture and family cultural capital. Educational Review, 55(2), 161-177.

Luke, A. \& Freebody, P. (1997). Critical literacy and the question of normativity: an introduction. In Muspratt, S., Luke, A. \& Freebody, P. (Eds.), Constructing Critical Literacies: Teaching and Learning Textual Practice. Language and Social Processes (pp. 1-18). Cresskill. N.J: Hampton Press.

McNaughton, S. (1995). Patterns of emergent literacy: processes of development and transition. Melbourne: Oxford University Press.

McNaughton, S. (2001). Co-Constructing Expertise: The Development of Parents' and Teachers' Ideas about Literacy Practices and the Transition to School, Journal of Early Childhood Literacy, 1(1), 40-58.

McNaughton, S. (2002). Meeting of minds. Wellington: Learning Media.

McNaughton, S. (2011). Designing Better Schools for Culturally and Linguistically Diverse Children: A Science of Performance Model for Research. London: Routledge.

McNaughton, S.; Amitanai-Toloa, M. \& Wolfgramm-Foliaki, E. (2009). Family literacy activities: what is, what ought to be and the role of parents' ideas. In FosterCohen, S (Ed.), Language Acquisition (pp. 319-336). New York : Palgrave Macmillan.

Merriam, S.B. (1998). Qualitative research and case study applications in education. San Francisco: Jossey-Bass.

Ministry of Education (2006). Effective Literacy Practice in Years 5 to 8. Wellington: Learning Media. 
Ministry of Education (2007). The New Zealand Curriculum. Wellington: Learning Media.

Ministry of Education (2008). The English Language Learning Progressions. Wellington: Learning Media.

Ministry of Education (2008). PIRLS 2005/2006 in New Zealand: A summary of national findings from the second cycle of the Progress in International Reading Literacy Study (PIRLS). Wellington: Comparative Education Research Unit.

Ministry of Education (2009). Reading and Writing Standards for Years 1-8. Wellington: Learning Media.

Ministry of Education (2009). National Education Monitoring Report 49 - Reading and Speaking Assessment Results 2008. Otago: University of Otago, Educational Assessment Research Unit.

Ministry of Education (2010). The Literacy Learning Progressions. Wellington: Learning Media.

Ministry of Education (2012). Education Counts. Retrieved September 26, 2012, from http://www.educationcounts.govt.nz/publications/schooling/2259/school-roll summary-report-july-2011)

Ministry of Education (2013). Pasifika Education Plan 2013-2017. Retrieved March 8,2014 , from

http://www.minedu.govt.nz/NZEducation/EducationPolicies/ /media/MinEdu/Files/E ducationSectors/PasifikaEducation/PasifikaEdPlan2013

Nakhid, C. (2002). "Intercultural" perceptions and institutional responses: Explaining Pasifika students' achievement in New Zealand secondary school. Unpublished doctoral thesis, Auckland University.

Openshaw, R. (2004). Is New Zealand's reading cup half full, or half empty? A final comment on the papers offered for the NZARE literacy symposium, 2003. Delta, 56(2), 109-118.

Nichols, S., \& Cormack, P. (2009). Making Boys at home in school? Theorising and researching (dis)connections. English in Australia, 44(3), 47-59.

Nieto, S. (2010). The light in their eyes: creating multicultural learning communities (10th ed.). New York: Teachers College Press.

Pahl, K. \& Rowsell, J. (2005). Literacy and education: understanding the new literacy studies in the classroom. London: Paul Chapman.

Pouono, J. (2009). Literacy begins in the fale. Journal of the Pacific circle consortium for Education, 21(2), 17-26. 
Rassool, N. (1999). Literacy: In search of a paradigm. In Literacy for sustainable development in the age of information (pp. 25-53). Clevedon, Avon: Multilingual Matters.

Rogoff, B. (1990). Apprenticeship in thinking: Cognitive development in social context. New York: Oxford University Press.

Rogoff, B. (1995). Observing sociocultural activity on three planes: Participatory appropriation, guided participation, and apprenticeship. In J. Wertsch, P. Del Rio \& A. Alvarez (Eds.), Sociocultural studies of mind (pp. 139-164). Cambridge: University of Cambridge.

Rogoff, B. (1998). Cognition as a collaborative process. In W. Damon, D. Kuhn \& R. Siegler (Eds.), Handbook of child psychology (5th ed., Vol. 2, pp. 679-744). New York: John Wiley \& Sons Inc.

Samu, T. W. (2006). The "Pasifika Umbrella' and Quality Teaching: Understanding and responding to the diverse realities within. Waikato Journal of Education, 12, 3549.

Statistics New Zealand (2006). Retrieved September 22, 2012, from http://www.stats.govt.nz/Census/2006CensusHomePage.aspx

Street, B. (1997). The implications of the "new literacy studies" for literacy education. English in Education, 31(3), 45-59.

Tagoilelagi, F. (1995). The role of the Samoan culture (Fa'asamoa) in the development of its children's literacy skills. Unpublished MA thesis, University of Auckland.

Tuafuti, P. (2000). Bridging the dichotomy between modern and traditional literacies in Samoan and English. Many Voices, 15, 10-14

Thrupp, M. (2013). National Standards for student achievement: Is New Zealand's idiosyncratic approach any better? Australian Journal of Language and Literacy, 36 (2), 99-110.

Tufulasi Taleni, L., Parkhill, F., Fa'afoi, A. \& Fletcher, J. (2007). Pasifika students: what supports them to become better readers? Pacific Asian Education, 19(2), 56-71.

Tunmer, W., Chapman, J.W., \& Prochnow, J.E. (2004). Why the reading achievement gap in New Zealand won't go away: Evidence from the PIRLS 2001 international study of reading achievement. New Zealand Journal of Educational Studies, 39(1), 127-145.

Vaioleti, T. M. (2006). Talanoa Research Methodology: A developing position on Pacific research. Waikato Journal of Education, 12, 21-3. 
APPENDICES 
Appendix A: Parent Background Information Sheet

\begin{tabular}{|l|l|l|l|l|l|l|l|}
\hline Parent & Gender & Age & Birthplace & Schooling & Employment & Arrival NZ & Children \\
\hline Parent Tasi & Female & 28 & $\begin{array}{l}\text { Upolu, } \\
\text { Samoa }\end{array}$ & Secondary & $\begin{array}{l}\text { Stay at home } \\
\text { Mother }\end{array}$ & 2001 & $\begin{array}{l}2 \text { daughters } \\
\text { 3 sons } \\
\text { (NZ born) }\end{array}$ \\
\hline Parent Lua & Female & 39 & $\begin{array}{l}\text { Savai'i, } \\
\text { Samoa }\end{array}$ & $\begin{array}{l}\text { Early } \\
\text { Secondary }\end{array}$ & Shift worker & 1982 & $\begin{array}{l}3 \text { daughters } \\
\text { s son } \\
\text { (NZ born) }\end{array}$ \\
\hline Parent Tolu & Female & 41 & $\begin{array}{l}\text { Upolu, } \\
\text { Samoa }\end{array}$ & $\begin{array}{l}\text { Early } \\
\text { Secondary }\end{array}$ & Factory work & 1987 & $\begin{array}{l}\text { 2 daughter } \\
\text { 2 sons } \\
\text { (NZ born) }\end{array}$ \\
\hline Parent Fa & Female & 32 & $\begin{array}{l}\text { Upolu, } \\
\text { Samoa }\end{array}$ & Secondary & WelTec & 2005 & $\begin{array}{l}1 \text { daughter } \\
\text { son } \\
\text { (1 born Samoa/1 NZ) }\end{array}$ \\
\hline Parent Lima & Female & 35 & $\begin{array}{l}\text { Savai'i, } \\
\text { Samoa }\end{array}$ & Secondary & Cleaner & 2011 & $\begin{array}{l}\text { 2 daughter } \\
\text { sons }\end{array}$ \\
\hline
\end{tabular}




\section{Appendix B: $\quad$ Talanoa Schedule for Parents}

The conversation (talanoa) format will take an open-ended approach that allows participants to share their stories and experiences in an informal way. There will a set of main questions formed to help guide the conversations between the participants and researcher. Some thought has been given to generating questions that will enable the usage of Rogoff's (1998) three planes - personal, interpersonal and community, for data analysis.

Examples of possible questions to be used with parent participants;

- What are your experiences/memories of learning to read in Samoa, at home and at school?

- What ways worked best for you when you were learning to read?

- What factors do you think are important when learning to read?

- How is learning to read in Samoa different from New Zealand?

- What type of reading activities do you and your child(ren) do at home?

- What do you see your role is in helping your child(ren) learn to read?

- Do others (people/institutions) help your child(ren) with learning to read?

- How does your child(ren) feel about learning to read?

- Do you know how learning to read happens at school?

- Does your child(ren) share their school reading experiences with you? 


\section{Appendix C: Talanoa Two Schedule for Parents}

\begin{tabular}{|c|c|}
\hline $\begin{array}{l}\text { At the pastors } \\
\text { school or Sunday } \\
\text { school }\end{array}$ & $\begin{array}{l}\text { What reading skills do you think the pastor or Sunday school teacher thought } \\
\text { were important to teach you, when learning to read? }\end{array}$ \\
\hline Reading the bible & $\begin{array}{l}\text { Were stories/verses linked to own lives? } \\
\text { Practice at home? Was the text discussed/meaning of stories-verses? }\end{array}$ \\
\hline Memory of text & Do you remember any of the names of the songs or poems? Books you read? \\
\hline $\begin{array}{l}\text { More on what is } \\
\text { important about } \\
\text { learning to read } \\
\text { and how }\end{array}$ & $\begin{array}{l}\text { This is a list of the ways of learning to read and what things are important } \\
\text { when learning to read (shared by you and the other participants) } \\
\text { Which ways when learning to read from this list are most important for you to } \\
\text { pass on to your own children? } \\
\text { (rank them for importance) } \\
\text { Which of these ways are used in your home? Examples. } \\
\text { Which ways did you think are used at school? Examples. } \\
\text { Are there any that are just for home or just for school? } \\
\text { Are there any other ways you would add to this list? } \\
\text { When you think of your own experiences of learning to read, what was good? } \\
\text { what was not so good? }\end{array}$ \\
\hline $\begin{array}{l}\text { Differences in the } \\
\text { teaching of } \\
\text { reading in Samoa } \\
\text { and NZ } \\
\text { Knowledge of } \\
\text { school practice } \\
\text { further }\end{array}$ & $\begin{array}{l}\text { Share list of the shared (mainly physical components) differences. } \\
\text { But if thinking about the reading skills, teachers in NZ are using to teach your } \\
\text { child, } \\
\text { What are these specific skills? } \\
\text { How are NZ teachers teaching reading? } \\
\text { And are they different to or the same as in Samoa? }\end{array}$ \\
\hline
\end{tabular}


Appendix D: Parent Talanoa Summary Lists

List of the things that are different about learning to read in Samoa

- Fewer resources

- Lots of time on the mat

- Only 1 teacher for the class, so no specialized assistance/teachers

- More children in classrooms

- Chalk board used a lot

- Lack of pre school education (done through Pastor's school and/or Sunday school)

- All children learning the same thing at the same time

- Less independent activities for children

- No reading books taken home (only homework exercise books)

- No school trips for primary aged children

- Teachers behaviour 
- Practising

- Listening to the teacher

- Repeating

- Learning the letter sounds

- Memorizing the sentence or story

- Concentrating

- Reciting (saying/performing) aloud

- Asking questions

- Answering questions about the story

- Understanding what you are reading, knowing what the story is about

- Using songs and poems 


\section{Appendix E: $\quad$ Talanoa Schedule for Students}

The student interviews will also use an informal conversation (talanoa) approach but may require the researcher to play a more active role in prompting the students for responses. Clear links between the parent and student questions will be formed to allow for triangulation of interview data.

Examples of possible questions to be used with student participants;

- What reading activities do you do at home by yourself? Or with mum or dad?

- Who helps you with reading at home? How do they help you?

- Do you like reading at home?

- What reading activities do you see your mum, dad or other family members do?

- How does mum or data help you understand what you are reading at home?

- Do you talk to your mum or dad about what you do during reading time at school?

- Has your mum or dad talked to you about how they learnt to read?

- Does your teacher and mum or dad do some of the same things when they are helping you with reading? Examples.

- What are some of the things that are different from reading at home and school? 


\section{Appendix F: $\quad$ INFORMATION SHEET FOR PRINCIPAL}

\section{The voices of Samoan parents and their children: home reading practices and home-school connections.}

I am completing my Masters Thesis at Victoria University this year and would like to gain approval to conduct my research project at Avalon School. I have selected Avalon School because of my established relationships with the school community and the large percentage of Samoan students attending at the present time.

\section{What is the research project?}

My research project will investigate the possible connections between home and school reading practices for primary school aged Samoan students. The voices of students and their parents will be used to gain insights into perceptions of reading practices.

\section{Who will be involved?}

1. School Principal - for permission to be approved to conduct the research project within the school and approach members of the school community.

2. Parents - 5-6 Samoan born adult participants who have been approached by the researcher as they fit the criteria selected.

3. Students - the eldest child of the adult participants who currently attends Avalon School.

All interviews with students would be scheduled at times that are convenient for the school and least disruptive for the classroom teacher and students. The parent participants will nominate the time and place for their interviews. The type of interview used, individual, pair or group will be selected by the parent participants. Some parents may wish to be interviewed with their partner.

\section{How will information be gathered?}

For the parent participants there will be an initial consultative parent meeting to outline the research project, answer any questions and gain consent for participation in the research project. There will be two talanoa (interview) sessions held with each parent. The students will be interviewed in pairs. It is expected that each parent interview session will be between 45 minutes to 1 hour. The student interviews between 30 to 45 minutes.

All participation is voluntary. Consent may be withdrawn at any time up until the end of the interview sessions. Data already collected from them will be destroyed. The information contained in the interviews and consent forms, will be stored securely in my supervisor's office at Victoria University for a period of 3 years. They will then be destroyed.

This research has been assessed and approved by Victoria University Faculty of Education Ethics Committee. If at any time you have any questions or concerns, you can contact Dr Allison Kirkman, Chair of the Victoria University of Wellington Human Ethics Committee at allison.kirkman@vuw.ac.nz

\section{What will happen with the data?}

The data gathered will be published for a wider academic audience through my final thesis, conferences or journal articles, but the identity of the school and participants involved will not be revealed at any 
point. Any responses that the parents and students give will be treated confidentially and I will protect their identities and the identity of the school through the use of pseudonyms and the removal of identifying details.

Transcribed interviews will be shown to all participants to check for accuracy and feedback before data analysis is done. I will transcribe the interviews and the content will be discussed with my supervisor. The findings of my research project will be shared with you and the Board of Trustees. It is hoped that the findings will provide the school with useful insights into home reading practices and add value to home-school partnerships.

If you agree to participate, please indicate this decision below and return the consent form to me. If you have any questions about this research or would like to discuss any concerns prior to providing consent, please feel free to contact me or my supervior at:

Thank you

Sarah Valentine

Email: valentsara1@myvuw.ac.nz

Phone: 021 2762228/04 9399600
Dr John Dickie (Supervisor)

Email: john.dickie@vuw.ac.nz

Phone: 044639767 


\section{Appendix G: $\quad$ CONSENT FORM FOR PRINCIPAL}

\section{The voices of Samoan parents and their children: home reading practices and home-school connections.}

I have read and understood the information letter from Sarah Valentine which describes her research project and I agree to Avalon School being part of the study.

- I give consent to this research project.

I understand that:

- Myself as the principal, and all research participants may withdraw their information up until the end of interviews and discussions.

- Participants' responses will be treated as confidential.

- The school participating, and the research participants will not be identified in the thesis nor in any publications or presentations.

- A copy of the research findings will be shared and discussed with the school and participants upon request.

- I can request a written summary of the final research findings.

- The research findings may be presented in academic or professional journals or at educational conferences.

- The research findings will be deposited in the university library as a Master's thesis.

- The research data will be securely stored at Victoria University and destroyed 3 years after the completion of the research project.

Principal's Name:

Principal's Signature:

Date: 


\section{Appendix H: INFORMATION SHEET FOR PARENTS}

\section{The voices of Samoan parents and their children: home reading practices and home-school connections.}

(to be shared and discussed during the initial parent meeting with parent participants)

\section{Talofa lava}

This year I am enrolled in the Master of Education programme at Victoria University and I would like to invite you to be a voluntary participant in my research project for my thesis.

\section{What is the purpose of my research?}

To listen to Samoan parents and their children's experiences of learning to read and home literacy practices. By listening to these ideas and experiences, it is possible that better connections and understandings between home and school reading practices might be made. This will benefit our school, as it will help us learn more about the cultural values and practices of our Samoan community.

I would also like to find out what one of your children (your eldest at Avalon School) sees as the connections between home and school reading practices.

\section{Why and how were you chosen?}

You are a Samoan born parent with experiences of schooling in Samoa, who has a child (or children) attending Avalon School. After our initial parent meeting you will asked if you would like to participate by sharing your home and school reading experiences with me.

\section{What will happen?}

After you give your consent to participate in my research project, I will meet with you for two talanoa (interview) sessions. You will be able to select the type of talanoa session, you would like to participate in. During the first talanoa session, I will ask you a number of questions about your own experiences of learning to read and your ideas about home and school reading practices. Our talanoa will be audiotaped and expected to take about an hour. At the second session, we have a chance to discuss your responses and make any changes necessary. You will be able to withdraw at any stage before our final talanoa session.

It will be important that you feel comfortable to talk and share your ideas. You do not have to discuss matters if you do not want to. What you share with me will only be used for the purpose of the research. The information will be stored securely in my supervisor's office at Victoria University for a period of three years. It will then be destroyed. Confidentiality will be maintained throughout the research process. My research will be used for my thesis, journal articles and conferences. All responses from you and your children will be treated confidentially and I will protect your identities and the identity of the school. 


\section{How do I agree to participate?}

You can give your consent to be part of my research by signing the Consent Form. I will also need to get consent from you to interview your eldest child attending Avalon School.

After our talanoa sessions, I will interview your eldest child. Their talanoa session will be with another child, to help them feel more comfortable and confident to share their experiences about reading at home and school. Your child will be able to choose if they would like to be involved or not.

Will I receive feedback on the findings of this research?

Yes, the findings will be shared with you and the other participants. A time will be arranged for this to happen once my thesis is finished. A summary report of the findings will also be shared with the Principal and Board of Trustees.

This research has been assessed and approved by the Victoria University Faculty of Education Ethics Committee. If you have any questions or would like further information about the research project, please contact me or my supervisor, Dr John Dickie, or the Chair of the Ethics Committee at Victoria University Dr. Allison Kirkman at allison.kirkman@vuw.ac.nz.

Fa'afetai lava

\section{Sarah Valentine}

Email: valentsara1@myvuw.ac.nz

Phone: 021 2762228/04 9399600
Dr John Dickie (Supervisor)

Email: john.dickie@vuw.ac.nz

Phone: 044639767 


\title{
Itulau Faaopoopo C: $\quad$ PEPA O FAAMATALAGA MO MĀTUA
}

\section{O leo o mātua Samoa ma a latou fanau: faatinoga o le faitau tusi i aiga ma so'otaga i aiga ma a'oga.}

\author{
(e soālaupule ma faatalanoaina i le taimi o le fonotaga muamua ma mātua auai)
}

\section{Talofa lava}

O le tausaga nei, o loo 'ou auai ai i le polokalame le Master of Education i le Iunivesite o Victoria, ma ua ou vala'aulia 'oe ina ia e auai mai i la'u su'esu'ega mo le faamaopoopoina o la'u mataupu autū, la'u thesis.

\section{O le a le autū o la'u su'esu'ega?}

Ina ia ou faalogo i mātua Samoa ma a latou fanau e faatatau i a latou masani i le a'oa'oina o le faitau atoa ai ma le faatinoga o le faitau tusi i o latou aiga. O le faalogo i nei manatu ma masani, e mafai ai ona faaleleia atili so'otaga ma le malamalama'aga i le va o aiga ma a'oga i le faatinoina o le faitau tusi. O le a aogā lea i la tatou a'oga, ona o le a fesoasoani ia i matou i le iloa atili o mea faatāuaina ma le faatinoga o tū ma aganu'u a tagata Samoa i lo tatou alalafaga.

Ou te fia iloa fo'i mai se tasi o ou alo (lau ulumatua o loo i le Avalon School) poo le a sona iloa i le so'otaga i le va o le aiga ma le a'oga i le faatinoga o le faitau tusi.

\section{Aiseā ma na faapefea ona tofia 'oe?}

O 'oe o se matua na fanau i Samoa e te silafia a'oga i Samoa ma e iai sou alo (poo sau fanau) o loo a'oga i Avalon School. I le mae'a ai o la tatou fonotaga muamua, o le a fesili atu pe e te fia auai e auala i le faasoa mai ia te a'u o lou silafia i le faitau tusi i totonu o lou aiga ma le a'oga.

\section{O le a leisi mea e tupu?}

A mae'a loa ona tu'uina mai lau maliega e te auai i la'u su'esu'ega, o le a faalua ona ta feiloa'i mo ni talanoaga. E mafai ona e filifili i le ituaiga talanoaga e te auai mai iai. I le talanoaga muamua, o le a 'ou fesili atu ia te 'oe poo le a sou silafia i le a'oa'oina o le faitau tusi atoa ai ma ni ou manatu i le faatinoga o le faitau tusi i totonu o aiga ma le a'oga. O le ta talanoaga o le a pu'eina i se lipine pu'e leo ma e fuafua i se itula le 'umi. I le talanoaga lona lua, o le a maua ai se avanoa ta te fetufaa'i ai i au tali na aumai ma faia ni suiga e mana'omia ona fai. E mafai ona e faamavae i soo se taimi lava ae le'i faia le talanoaga mulimuli.

E tāua tele ona e fiafia e te talanoa ma faasoa mai ou manatu. E le faamalosia 'oe e faaali sou manatu i se mataupu e te le fia talanoa iai. O mea uma e te faasoaina mai ia te a'u, o le a na o le autū lava o la'u su'esu'ega e faaogāina ai. O faamatalaga uma o le a teu malu i le ofisa o le faia'oga o loo pulea la'u mataupu i le Iunivesite o Victoria mo le tolu tausaga. A mae'a lea taimi ua faatāma'ia loa. O faamatalaga uma e malu puipuia i le taimi atoa o le su'esu'ega. O la'u su'esu'ega e faaogāina mo la'u mataupu tusitusia (thesis), tusitusiga i lomiga faapitoa ma fonotaga. O tali uma mai ia te 'oe ma lau fanau o le a 
malu puipuia, ma o le a puipuia fo’i le faaalia o lou suafa ma igoa o lau fanau, atoa ai ma le igoa o le a'oga.

\section{E faapefea ona faailoa la'u maliega ou te auai?}

E mafai ona aumai lau maliega e te auai i la'u su'esu'ega e auala i lou sainia o le Pepa o Maliega. Ou te mana'omia fo'i lau maliega ou te talanoa ai i lou alo ulumatua o loo a'oga i Avalon School.

A mae'a a ta talanoaga, ona ma talanoa lea ma lou alo ulumatua. O le talanoaga ma lou alo, o le a auai iai ma seisi tamaititi e faafaigofie ai ona fiafia ma loto tele e faasoa mai o la manatu i le faitau tusi i totonu o aiga ma a'oga.

Ou te mauaina mai ni faamatalaga i faai'uga o lenei su'esu'ega?

Ioe, o faai'uga o lenei su'esu'ega o le faasoa atu ia te 'oe ma isi tagata na auai. O le a faatulaga se taimi e faia ai pe a mae'a ona tusia la'u mataupu (thesis). O se lipoti fo'i o le aotelega o faai'uga o le a faasoa i le Pule A'oga ma le Komiti Faafoe, le Board of Trustees.

O lenei su'esu'ega na iloiloina ma faatagaina e le Komiti, le Victoria University Faculty of Education Ethics Committee. A iai ni au fesili pe e te fia maua nisi faamatalaga i lenei su'esu'ega, faamolemole faafeso'ota'i mai a'u poo le faia'oga pule i la'u mataupu Dr John Dickie, poo le ta'ita'ifono o le Ethics Committee i le Iunivesite o Victoria Dr Allison Kirkman, i le allison.kirkman@vuw.ac.nz.

Fa'afetai lava

\section{Sarah Valentine}

Email: valentsara1@myvuw.ac.nz

Phone: 021 2762228/04 9399600
Dr John Dickie (Supervisor)

Email: john.dickie@vuw.ac.nz

Phone: 044639767 


\section{Appendix I: $\quad$ CONSENT FORM FOR PARENTS}

- I have read and understood the participant information sheet that describes the research project.

- I understand that the information I give Sarah will be confidential and that no names (mine, my child's or the school's) will be used in the final report for her thesis.

- I understand that I have the right to see the written transcript of our talanoa session and the opportunity to make changes if I think it is necessary.

- I understand that I have the right to withdraw up until the end of our talanoa sessions.

- I understand that the research findings will be shared with the school.

- I understand that the research data will be securely stored at Victoria University and destroyed 3 years after the completion of the research project.

I am willing to be involved in Sarah Valentine's research project.

Parent Name:

Parent Signature:

Date: 


\section{CONSENT FORM FOR PARENTS (for their child to participate in the research project)}

- I have read and understood the student participant information sheet that describes the research project and I agree to let my child participate.

- I understand that permission has been given by the Principal for this research project to take place.

- I understand that the name of my child and the school's name will remain confidential to Sarah.

- I understand that my child's ideas will be audiotaped and written down.

- I understand that my child has the right to withdraw up until the end of their talanoa session with Sarah.

I give permission for

to be involved in Sarah Valentine's research project.

Parent Name:

Parent Signature:

Date: 


\section{Pepa Faaopoopo D: $\quad$ PEPA O MALIEGA MO MĀTUA}

- Ua 'ou faitauina ma ua 'ou malamalama i le pepa o faamatalaga o loo faamatala mai ai le su'esu'ega.

- Ua 'ou malamalama o faamatalaga uma ou te avatua ia Sarah e puipuia ma e leai ni igoa (lo’u igoa, igoa o la'u fanau, poo le a'oga) o le a faaogāina i le lipoti mulimuli o lana mataupu tusitusia (thesis).

- Ou te malamalama e iai la'u aiā ou te va'ai ai i se kopi tusitusia o a ma talanoaga atoa ai ma avanoa e fai ai ni suiga ou te manatu e mana'omia.

- Ou te malamalama e iai la'u aiā ou te faamavae ai i soo se taimi e tau lava i le faai'uga o a ma talanoaga.

- Ou te malamalama o faai'uga o lenei su'esu'ega o le a faasoa ma le a'oga.

- Ou te malamalama o faamaumauga uma i lenei su'esu'ega o le a teu malu i le Iunivesite o Victoria ma o le a faatāma'ia i le tolu tausaga talu ona mae'a le su'esu'ega.

O a'u ua ou malie ou te auai i le su'esu'ega a Sarah

Valentine.

Suafa o le Matua:

Saini a le Matua:

Aso: 


\section{PEPA O MALIEGA MO MĀTUA (ina ia auai ai lona alo i lenei su'esu'ega)}

- Ua 'ou faitauina ma ua 'ou malamalama i le pepa o faamatalaga mo tamaiti a'oga o loo faamatala mai ai le su'esu'ega, ma ua 'ou malie e auai iai la’u tama.

- Ou te malamalama ua aumai le faatagaga mai le Pule A'oga e faia ai lenei su'esu'ega.

- Ou te malamalama o le igoa o la'u tama ma le igoa o le a'oga o le a puipuia e Sarah.

- Ou te malamalama o manatu o la'u tama o le a pu'eina i se lipine pu'e leo ma tusia i lalo.

- Ou te malamalama e iai le aiā a la'u tama e faamavae ai i soo se taimi e tau i le faai'uga o a la talanoaga ma Sarah.

Ou te avatu le faatagaga mo e auai ai i le su'esu'ega a Sarah Valentine.

Suafa o le Matua:

Saini a le Matua:

Aso: 


\section{Appendix J: $\quad$ INFORMATION SHEET FOR STUDENTS}

\section{The voices of Samoan parents and their children: home reading practices and home-school connections.}

(this sheet will be read aloud to each student participant)

Talofa lava

This year I am studying at University. One of my jobs is to do a research project about something that I am interested in. So my research project is going to be about the reading experiences and ideas of Samoan parents and their children.

I am interested in asking you some questions about reading at home and at school. I want to find out what sort of reading activities you do at home and what is the same or different about reading at home and school.

I will meet with you and a buddy (who will be Samoan like you) to share your ideas and experiences.

I will audiotape your ideas using my laptop and share them back with you, so you can add or change any answers if you want to. It is your choice if you would like to participate or not. During our talk you can decide to withdraw at any time if you wish.

Fa'afetai lava

Sarah

Sarah Valentine

Email: valentsara1@myvuw.ac.nz

Phone: 021 2762228/04 9399600
Dr John Dickie (Supervisor)

Email: john.dickie@vuw.ac.nz

Phone: 044639767 
Appendix K: $\quad$ CONSENT FORM FOR STUDENTS

(this form will be read aloud to each student participant)

- Sarah has read the information sheet to me and I understand it.

○ My ideas and experiences will be audiotaped and then written down.

- I will have a chance to check my answers to Sarah's questions with her.

- Sarah will share my ideas with people (my parents, my school and others) who are interested in what I have to say.

- My name or the school's name will not be used.

- I do not have to be part of Sarah's research project if I decide not to be and withdraw before our interview finishes.

\section{Student's Name:}

Student's Signature:

Date: 